\title{
Birthweight: EN-BIRTH multi-country validation study
}

Stefanie Kong ${ }^{1 \dagger}$, Louise T. Day ${ }^{1 *}$, Sojib Bin Zaman², Kimberly Peven ${ }^{1,3}$, Nahya Salim, ${ }^{4,5}$, Avinash K. Sunny ${ }^{6}$, Donat Shamba ${ }^{5}$, Qazi Sadeq-ur Rahman², Ashish K.C. , Harriet Ruysen', Shams El Arifeen², Paul Mee ${ }^{8}$, Miriam E. Gladstone ${ }^{1}$, Hannah Blencowe ${ }^{1 \dagger}$, Joy E. Lawn ${ }^{1 \dagger}$ and EN-BIRTH Study Group

\begin{abstract}
Background: Accurate birthweight is critical to inform clinical care at the individual level and tracking progress towards national/global targets at the population level. Low birthweight (LBW) $<2500 \mathrm{~g}$ affects over 20.5 million newborns annually. However, data are lacking and may be affected by heaping. This paper evaluates birthweight measurement within the Every Newborn Birth Indicators Research Tracking in Hospitals (EN-BIRTH) study.

Methods: The EN-BIRTH study took place in five hospitals in Bangladesh, Nepal and Tanzania (2017-2018). Clinical observers collected time-stamped data (gold standard) for weighing at birth. We compared accuracy for two data sources: routine hospital registers and women's report at exit interview survey. We calculated absolute differences and individual-level validation metrics. We analysed birthweight coverage and quality gaps including timing and heaping. Qualitative data explored barriers and enablers for routine register data recording.

Results: Among 23,471 observed births, 98.8\% were weighed. Exit interview survey-reported weighing coverage was $94.3 \%$ (90.2-97.3\%), sensitivity 95.0\% (91.3-97.8\%). Register-reported coverage was 96.6\% (93.2-98.9\%), sensitivity $97.1 \%$ (94.3-99\%). Routine registers were complete (> 98\% for four hospitals) and legible > 99.9\%. Weighing of stillbirths varied by hospital, ranging from 12.5-89.0\%. Observed LBW rate was 15.6\%; survey-reported rate $14.3 \%$ (8.9-20.9\%), sensitivity $82.9 \%$ (75.1-89.4\%), specificity 96.1\% (93.5-98.5\%); register-recorded rate 14.9\%, sensitivity 90.8\% (85.9-94.8\%), specificity 98.5\% (98-99.0\%). In surveys, "don't know" responses for birthweight measured were $4.7 \%$, and $2.9 \%$ for knowing the actual weight. $95.9 \%$ of observed babies were weighed within $1 \mathrm{~h}$ of birth, only $14.7 \%$ with a digital scale. Weight heaping indices were around two-fold lower using digital scales compared to analogue. Observed heaping was almost 5\% higher for births during the night than day. Survey-report further increased observed birthweight heaping, especially for LBW babies. Enablers to register birthweight measurement in qualitative interviews included digital scale availability and adequate staffing.

(Continued on next page)
\end{abstract}

\footnotetext{
* Correspondence: Louise-Tina.Day@lshtm.ac.uk

†Stefanie Kong and Louise T Day are joint first authors.

${ }^{\dagger}$ Hannah Blencowe and Joy E Lawn are joint senior authors.

'Centre for Maternal, Adolescent, Reproductive \& Child Health (MARCH),

London School of Hygiene \& Tropical Medicine (LSHTM), London, UK

Full list of author information is available at the end of the article
}

\section{$\triangle B M C$}

C) The Author(s), 2021 Open Access This article is licensed under a Creative Commons Attribution 4.0 International License which permits use, sharing, adaptation, distribution and reproduction in any medium or format, as long as you give appropriate credit to the original author(s) and the source, provide a link to the Creative Commons licence, and indicate if changes were made. The images or other third party material in this article are included in the article's Creative Commons licence, unless indicated otherwise in a credit line to the material. If material is not included in the article's Creative Commons licence and your intended use is not permitted by statutory regulation or exceeds the permitted use, you will need to obtain permission directly from the copyright holder. To view a copy of this licence, visit http://creativecommons.org/licenses/by/4.0/ The Creative Commons Public Domain Dedication waiver (http://creativecommons.org/publicdomain/zero/1.0/) applies to the data made available in this article, unless otherwise stated in a credit line to the data. 
(Continued from previous page)

Conclusions: Hospital registers captured birthweight and LBW prevalence more accurately than women's survey report. Even in large hospitals, digital scales were not always available and stillborn babies not always weighed. Birthweight data are being captured in hospitals and investment is required to further improve data quality, researching of data flow in routine systems and use of data at every level.

Keywords: Birth, Newborn, Maternal, Stillbirth, Coverage, Validity, Survey, Health management information systems, Birthweight, Low birthweight

\section{Key findings}

\section{What is known and what is new about this study?}

- An estimated 20.5 million low birthweight (LBW) babies are born each year, and tracking progress in the highest burden countries still relies on population-based surveys, which are known to have missing data and substantial heaping (preference for recording weights ending in 00). Improving birthweight data in both routine systems and surveys is essential.

- EN-BIRTH is the largest multi-country, multi-site study $(>23,000$ births) to assess availability, validity and quality of birthweight data in both survey and routine registers. Qualitative data explored barriers and enablers for routine register recording of birthweight.

\section{Survey-what did we find and what does it mean?}

- Survey-reported birthweight coverage underestimated observed coverage by nearly $5 \%$ and LBW prevalence by $1 \%$.

- Survey-reported birthweight heaping was 1.5 times higher than the observed heaping.

- Women with stillborn babies reported a much lower coverage of weighing than observed.

\section{Register-what did we find and what does it mean?}

- Routine hospital registers were highly complete (>96\%) and legible (> 99\%).

- Register-recorded birthweight coverage underestimated observed by $2.2 \%$.

- LBW prevalence underestimated observed by only $0.7 \%$.

- Register-reported birthweight heaping at $2500 \mathrm{~g}$ further increased observed heaping by $1.4 \%$ for digital scales and $1.1 \%$ for analogue.

\section{Gap analysis for quality of care}

- Nearly all (95.9\%) babies were weighed within 1 h, however, only 14.7\% were weighed on digital scales. Stillbirths were weighed much less often, despite birthweight data being fundamental to classifying and intervening to prevent stillbirth.

- Substantial heaping of observed birthweights included those at $2500 \mathrm{~g}$, so the LBW rate will likely be inaccurate.

- Birthweight heaping indices were approximately two-fold lower using digital compared to analogue scales and also 3-5\% lower during day shifts compared to night shifts.

\section{What next and research gaps?}

- Routine register-records outperformed exit-survey report accuracy for measurement of birthweight and LBW in these hospitals. Further research is needed to assess if survey-reported accuracy decreases over time.

- Investment is needed to explore how digital scales, standardised register process and design can improve birthweight routine data measurement quality further.

- Improving data flow of currently available hospital birthweight data into Health Management Information Systems (HMIS) has potential to close the large LBW data gap in high-burden LMIC settings.

\section{Background}

Birthweight closely correlates with newborn survival and lifelong health. The World Health Organization (WHO) recommends measuring birthweight within the first hour of life, ideally using calibrated digital scales with 10 gramme (g) precision [1]. Low birthweight rate has agreed global targets and data are needed to track progress [2]. Among neonatal deaths, $80 \%$ have low birthweight (LBW) defined as $<2500 \mathrm{~g}[3,4]$. An estimated 20.5 million LBW neonates were born in 2015; 91\% were born in lowand middle-income countries (LMICs), with almost half in south Asia (48\%) and a quarter in sub-Saharan Africa (24\%) $[3,5]$. LBW survivors continue to have a higher risk of morbidity, including stunting, lower intelligence quotient, and cardiovascular disease later in life [6-8]. Stillborn babies, estimated at $>2$ million per year and $84 \%$ in LMICs, have similar contributing factors to placental failure as LBW livebirths, yet are not visible as standard birthweight indicator definitions use a livebirth denominator [9].

Tracking coverage of birthweight measurement is recommended and LBW rate is one of only four newborn health measures in WHO's 100 core health indicators [10]. Global nutrition targets set by WHO include a 30\% reduction of LBW infants from 2012 to 2025 [2], but the required annual rate of reduction is currently off target [11]. Birthweight data are essential to reach the target neonatal mortality rate (NMR) of Sustainable Development Goal (SDG) 3.2 by 2030 [12]. NMR and stillbirth rates stratified by birthweight group need to be used for perinatal death surveillance and response in settings where accurate gestational age and cause of death assessment is not possible [13]. At an individual level, birthweight data ensures that at-risk newborns receive the immediate care they need and serves as the first measurement for monitoring a child's growth to promote health outcomes throughout the lifecourse.

Birthweight data are not available for almost one-third (39.7 million) of newborns - the majority in LMICs [3]. Available birthweight data in high mortality burden countries are mostly from population-based surveys, notably the Demographic and Health Surveys (DHS) Program and the United Nations Children's Fund (UNICEF) Multiple 
Indicator Cluster Surveys (MICS) [14, 15]. As $>80 \%$ of births globally are now in facilities [15], potentially more birthweight data can be made available through routine Health Management Information Systems (HMIS) [4, 14]. When birthweight data are available, concerns about quality, including heaping, limit use and usefulness. Previous birthweight-related indicator validation studies in LMICs have mostly focused on household survey measurement [16-19], with few addressing routine facility measurement [20]. The validity of birthweight measurement through routine hospital registers in LMIC has not previously been studied. The barriers and enablers that affect the quality of birthweight data in routine hospital registers in LMIC are not known.

The Every Newborn Action Plan, agreed by all United Nations member states and $>80$ development partners, includes an ambitious measurement improvement roadmap $[12,21]$ with urgent focus to improve data for use towards high-quality care around the time of birth $[12,22]$. As part of this roadmap, the Every Newborn Birth Indicators Research Tracking in Hospitals (EN-BIRTH) study aimed to validate the measurement of selected newborn and maternal indicators for routine tracking of coverage and quality of facility-based care $[23,24]$.

\section{Objectives}

This paper is part of a supplement based on the ENBIRTH multi-country validation study, 'Informing measurement of coverage and quality of maternal and newborn care', and focuses on birthweight with three objectives:

1. Determine accuracy/validity of NUMERATOR for survey-reported and register-recorded birthweight indicator measurement compared to direct observation.

2. Analyse GAPs in coverage and quality of birthweight measurement: timeliness, scale choice, proportion of implausible values and heaping/rounding inaccuracy.

3. Identify BARRIERS and ENABLERS for routine register recording of birthweight by evaluating register design, filling and use.

\section{Methods}

The EN-BIRTH study was a mixed-methods observational study and detailed information regarding the EN-BIRTH research protocol and overall validation results have been published separately [23, 24]. This is the first analysis of the EN-BIRTH birthweight data. A study on birthweight measurement processes and perceived value is published elsewhere in the supplement [25]. Data were collected between June 2017 and July 2018 in five public comprehensive emergency obstetric and newborn care (CEmONC) hospitals in three high burden countries: Maternal and Child Health Training Institute (MCHTI), Azimpur and Kushtia District Hospital in Bangladesh (BD); Pokhara Academy of Health Sciences in Nepal (NP); Temeke Regional Hospital and Muhimbili National Referral Hospital in Tanzania (TZ) (Additional files 1 and 2). Results are reported in accordance with STROBE Statement checklists for observational studies (Additional file 3).

Study participants were consenting women recruited on admission to labour and delivery ward and their newborn babies. We use the term "newborn" in this paper to cover both live births and stillbirths (total births). Exclusion criteria at admission were imminent birth and no fetal heartbeat heard. Trained research clinical observers collected the birthweight from the weighing scale (external gold standard) as the health worker weighed the newborn. Data were time-stamped when documenting birthweight in grammes and type of weighing scale (digital or analogue). Separate groups of data extractors captured birthweight data from existing routine labour ward registers and women's responses to exit-survey after discharge. Data were captured using a custom-built android tablet-based application [26] (Additional file 5).

Implausible observed birthweights $(<350 \mathrm{~g}$ or $>6000 \mathrm{~g})$ were excluded from all analyses. Calculations were done for each hospital then combined using a random effects meta-analysis approach. We used $95 \%$ confidence intervals to indicate uncertainty when applying our results to a different population. We calculated $\mathrm{I}^{2}$ and $\tau^{2}$ to assess heterogeneity between hospitals. Results were stratified by mode of birth (vaginal/caesarean), birth outcome (live birth/stillbirth), and type (single/multiple (twins or higher)) and association determined using chi-squared test.

Analyses were undertaken using Stata version 16 [27] and $\mathrm{R}$ statistical programming version 3.5.0 used for graphs [28].

\section{Assessing biases in the data}

To determine the reliability of our gold standard, we calculated Cohen's Kappa coefficient for $5 \%$ of the sample observed by both supervisors and data collectors [23]. To assess any change in routine register recording practices due to study observer presence, we compared absolute differences between completeness of register extracted study data with one-year pre-study register data collected retrospectively [29]. We also calculated Kappa coefficients for a $5 \%$ sample of double-extracted study register data.

\section{Objective 1: Determine numerator for indicator measurement accuracy/validity}

We evaluated measurement of two aspects of birthweight data: 
a) Birthweight coverage defined as the number of facility total births (live births and stillbirths) that were weighed, among total births, expressed as a percentage.

b) $\boldsymbol{L B W}$ prevalence defined as the number of facility total births (live births and stillbirths) whose birthweights were $<2500 \mathrm{~g}$, among total births weighed, expressed as a percentage.

To assess data accuracy, we compared both routine register-recorded coverage and exit interview surveyreported coverage with the gold standard, observed coverage (Fig. 1). Population-based surveys (e.g. DHS and MICS) typically measure coverage from "yes" responses and combine "don't know" with "no" responses as "no coverage." Thus, we analysed survey-reported coverage in this way and also with "don't know" excluded to evaluate effect on accuracy. We interpreted register "not recorded" to mean the baby had not been weighed. LBW classification was calculated using available numeric birthweight data from all three sources.

We calculated absolute differences between observed, register-recorded and exit survey-reported coverage. Cut-off ranges were adapted from WHO's Data Quality Review (DQR) methods (over/underestimate by $0-5 \%, 6-$ $10 \%, 11-15 \%, 16-20 \%$ and $>20 \%)[30,31]$.
To understand how coverage measurement affected low and normal birthweight categorisation, we calculated "validity ratios". Similar to verification ratios in DQR methods [30], a ratio higher than 1.0 implies overestimation of survey-reported or register-recorded coverage compared to observed, and a ratio lower than 1.0 implies an underestimate. Cut-off ranges adapted from DQR methods were used for heat-maps [30].

Individual-level validity "diagnostic test" methods were calculated using two-way tables. When column totals were $\geq 10$, we calculated sensitivity, specificity, negative predictive value, positive predictive value, area under the curve and inflation factor; otherwise we present percent agreement [23, 32]. Individual-level agreement was assessed using Bland-Altman plots [33].

\section{Objective 2: Gaps in coverage and quality of birthweight measurement}

We calculated gap analyses for high-quality birthweight among (A) total births as the total eligible population; (B) birthweight coverage; (C) right timeliness of measurement - weighed $\leq 1 \mathrm{~h}$ after birth; (D) right device - digital scales.

Data completeness for registers was assessed. Birthweight heaping and rounding were evaluated for observed, survey-reported and register-recorded data in two ways: First, the proportion of total birthweights that

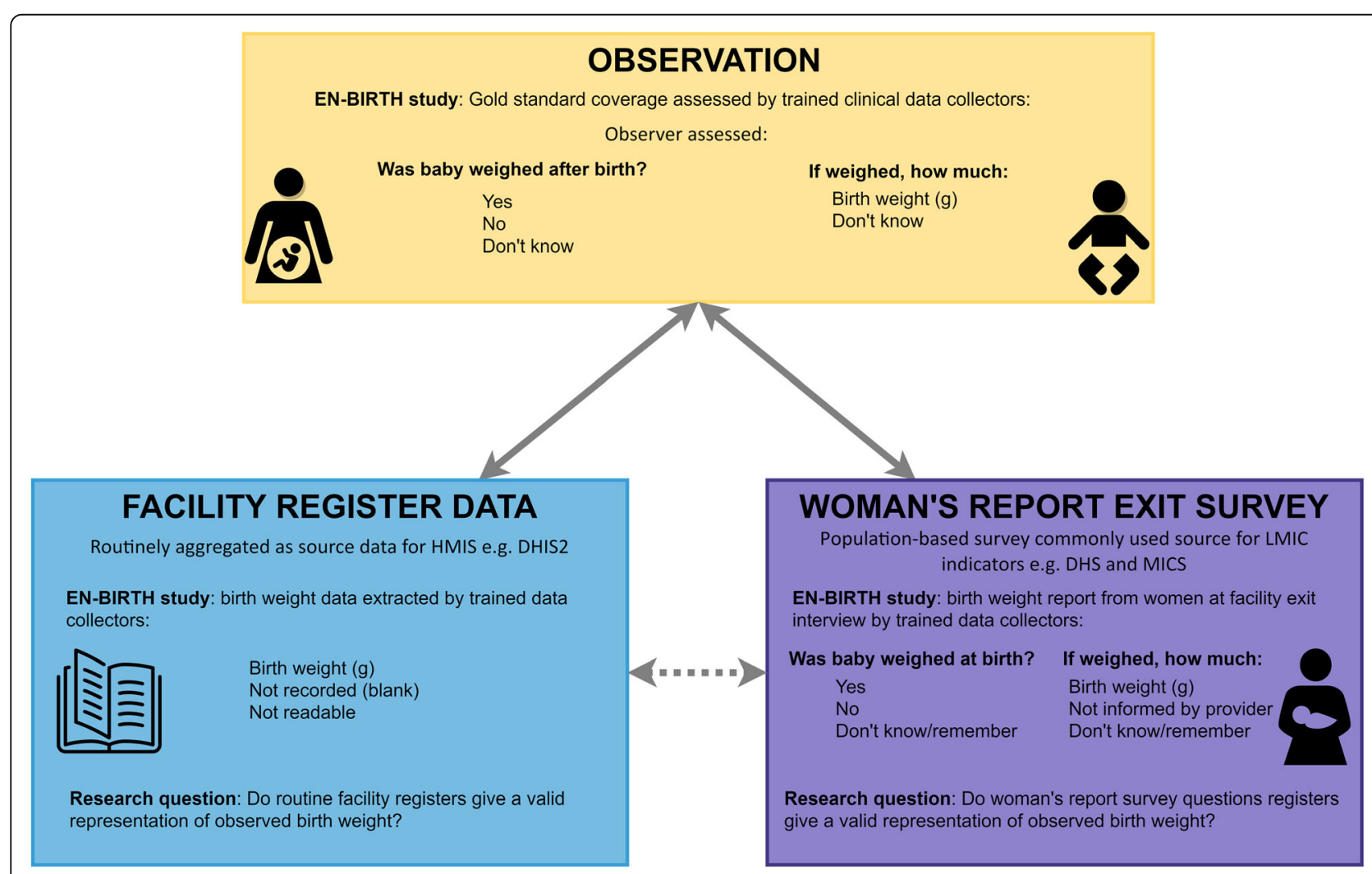

Fig. 1 Birthweight validation design, EN-BIRTH study. Adapted from EN-BIRTH protocol [23] 
were multiples of $500 \mathrm{~g}$; second, the proportion of heaped weight values (e.g. $2500 \mathrm{~g}$ ) relative to all weight values within the adjacent $500 \mathrm{~g}$ bracket (e.g. 2250-2750 g). We stratified by type of weighing device and time of birth by midwifery shift time (day/night). To demonstrate the effect of heaping on LBW prevalence in routine register documentation, we adjusted LBW prevalence by reallocating $25 \%$ of babies with an exact birthweight of $2500 \mathrm{~g}$ to the LBW category and compared with exit-survey findings using the same method [34].

\section{Objective 3: Barriers and enablers to routine register recording}

We evaluated barriers and enablers to recording of birthweight in routine registers as part of the wider barriers and enablers objective of the EN-BIRTH study. The structure of the routine labour ward register was correlated with completeness and accuracy of measurement [31].

We designed three tools: a) semi-structured in-depth interview (IDI) guide, b) semi-structured focus group discussion (FGD) guide, c) "care-to-documentation checklist."

Experienced qualitative researchers conducted IDIs with two purposively sampled groups of respondents in each EN-BIRTH study hospital: 1) hospital midwives and doctors involved in birthweight measurement and 2) study data collectors. To triangulate results, FGDs were carried out with health workers. The sample size was determined using saturation sampling. Qualitative data were thematically analysed by categorizing pre-identified codes based on the Performance of Routine Information System Management (PRISM) conceptual framework [35] using NVivo 12 for data management. The care-to-documentation checklist was completed after the IDI and captured details regarding: which health worker cadre weighs the baby; who documents the birthweight; into which documents (patient notes, registers, partograph, etc.); the typical order of documentation; estimation of how long between weighing the baby and documentation. Data were entered into Microsoft Excel and analysed in R version 3.6.1 [28]. This paper specifically presents emerging themes regarding birthweight recording across three topics: 1) Register design 2) Register filling and 3) Register use. Detailed methods and results of all emerging themes for register recording of all EN-BIRTH selected indicators are available in an associated paper [36].

\section{Results}

Among the total 23,471 births observed, 22,617 (96.3\%) newborns were weighed after birth and implausible weights were $0.01 \%$ (Additional file 4). Exit-survey interviews were completed by $88.4 \%$ of their mothers and register data were extracted for $95.3 \%$ (Fig. 2).
Background characteristics are shown in Table 1. $12.1 \%$ of mothers were adolescents $<20$ years and almost half of women (48.4\%) had completed secondary education. Live births were $97.3 \%$ and twins/triplets $3.9 \%$. The proportion of babies delivered by caesarean section varied widely, from $7.2 \%$ in Temeke $\mathrm{TZ}$ to $73.2 \%$ in Azimpur BD. Hospital register design in Bangladesh was updated during the study as part of a national standardisation - we present revised register results in the multi-site tables and figures and report the effect of this natural experiment in Additional file 6.

Inter-rater reliability was very high for both observation and data extraction (Additional file 7). Routine register completeness comparison before and during study showed decrease in completeness by $<1.5 \%$, except in Kushtia BD, which increased from $66.1 \%$ to $85.2 \%$ (Additional file 8).

Coverage data by observation, survey-report and register-record are shown in Fig. 3. Coverage comparisons and individual-level metrics are shown in Tables 2 and 3. Any association with delivery mode, multiple births, and stillbirth are shown in Additional files 9, 10 and 11.

\section{Objective 1: Numerator validation Birthweight coverage}

Survey-reported coverage, $94.3 \% \quad$ (90.2-97.3\%), underestimated the observed coverage of $98.8 \%$. Exitsurvey heterogeneity was low, $\tau^{2}=0.03$ (Additional file 12). "Don't know" responses were $4.5 \%$ (2.1-8.4\%) and pooled individual-level validation results were mixed: sensitivity $95.0 \%$ (91.3-97.8\%), specificity $43.3 \%(15.1-74.0 \%)$. There was no evidence of a difference in survey-reported coverage by delivery mode or single/multiple pregnancy. Across the sites, stillbirth observed birthweight coverage ranged from $12.5-98.3 \%$, and survey-report underestimated by $8.2-$ 46.6\% (Additional file 10).

Register-recorded coverage of $96.6 \%$ (93.2-98.9\%) underestimated the observed coverage of $98.8 \%$. Heterogeneity was low, $\mathrm{\tau}^{2}=0.03$ (Additional file 12). In Temeke $\mathrm{TZ}$, coverage was overestimated by $0.1 \%$ and in the other four hospitals underestimated by $0.3-12.1 \%$. Sensitivity was $>88 \%$ and specificity ranged from $3.5 \%$ in Muhimbili $\mathrm{TZ}$ to $82.0 \%$ in Kushtia BD. Register-recorded coverage was significantly higher among babies born from vaginal deliveries compared to caesarean section, as well as live births compared to stillbirths (Additional files 10 and 11).

\section{Low birthweight (LBW) prevalence}

Observed LBW prevalence overall was $15.6 \%$, lowest in Temeke TZ 7.6\% and highest in Muhimbili TZ 28.1\%. Survey-reported LBW coverage, 14.3 (8.9-20.9\%), underestimated observed coverage of $15.6 \%$. "Don't know" 


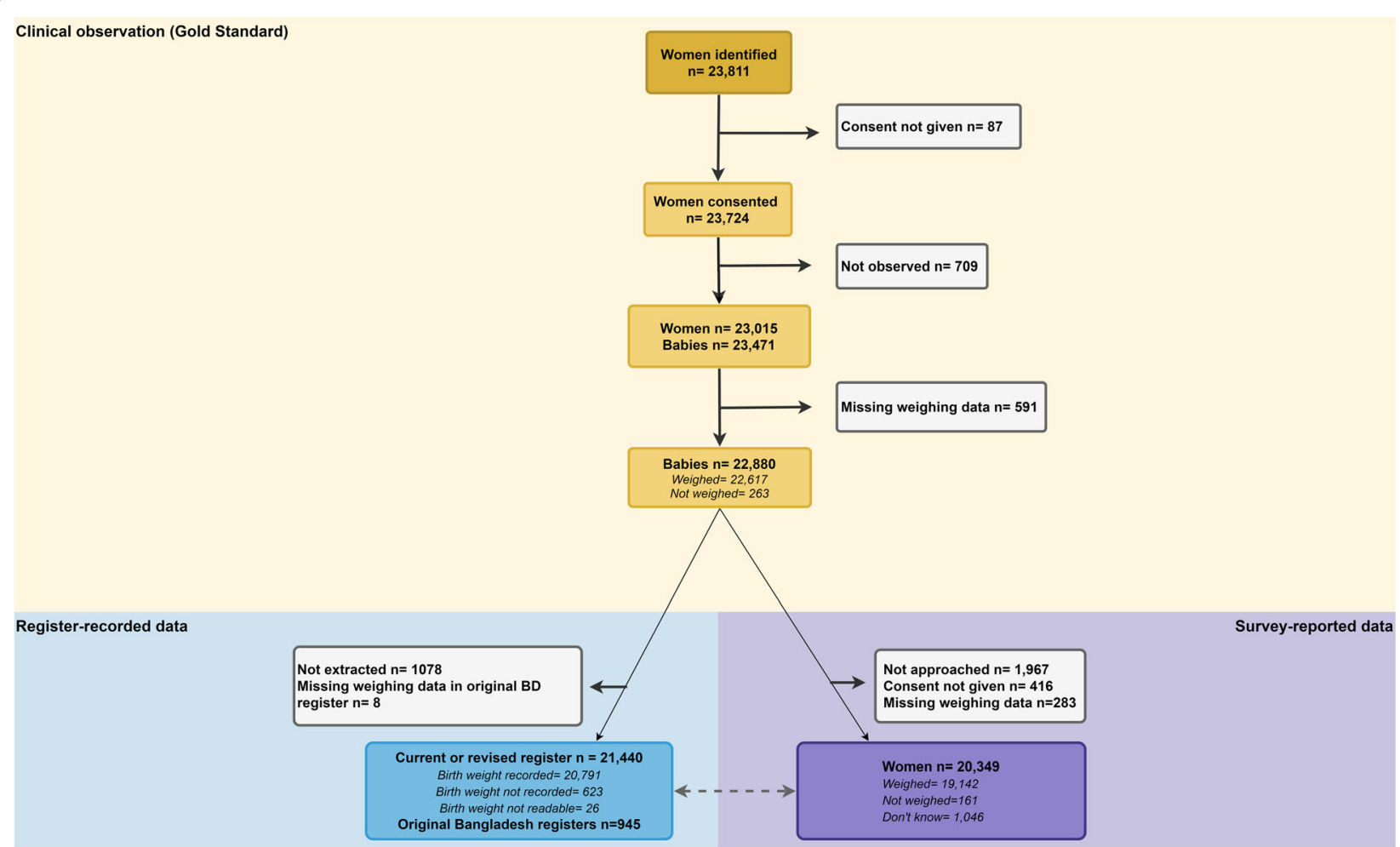

Fig. 2 Flow diagram for birthweight cases, EN-BIRTH study $(n=23,471)$. Adapted from EN-BIRTH protocol [23]

survey responses were $2.9 \%$ (1.8-4.3\%). Sensitivity was 82.9\% (75.1-89.4\%) and specificity 96.4\% (93.5-98.5\%). LBW observed among stillborn babies ranged widely from $0.0-75.5 \%$, both over- and underestimated by survey-report in different sites.

Register-recorded LBW coverage of 14.9\% (8.8-22.3\%) underestimated observed coverage, 15.6\%. Register sensitivity was $90.8 \%(85.9-94.8 \%)$ and specificity $98.5 \%$ (98.0-99.0\%). Both survey-reported and registerrecorded LBW coverage were higher among caesarean sections, stillbirths, and twins/triplets.

Survey-reported validity ratios for LBW babies were poor to good (0.78-1.62) and very good to excellent (0.91-1.08) for normal birthweight (Fig. 4). Registerrecorded validity ratios were excellent (0.99-1.03) for both LBW and normal birthweight newborns.

Bland-Altman plots showed agreement between observed and survey-reported birthweight was reasonable, with mean difference $=6.3 \mathrm{~g}(2.7,9.9)$, and for registerrecorded was high, with mean difference $=-1.39 \mathrm{~g}(-4.4$, 1.6) (Additional file 13).

\section{Objective 2: Gaps in coverage and quality of birthweight measurement}

Figure 5 shows gap analyses linked to coverage measurement. Almost all newborns (95.9\%) were observed to be weighed within the right time $(\mathrm{C}), 1 \mathrm{~h}$ of birth. Digital scales as the right device (D) were used in only three of the hospitals: Azimpur BD (74.2\%), Muhimbili TZ (29.3\%) and rarely in Temeke TZ (2.0\%) (Additional file 14).

Register-recorded birthweight was legible (Fig. 6). Completeness was very high (>98\%) in all hospitals, except in Kushtia BD (85.5\%). Completeness was higher in Bangladesh revised registers compared to the original: Azimpur $\mathrm{BD}=98.4 \%$ from $57.4 \%$ and Kushtia $\mathrm{BD}=$ 85.2\% from 43.8\% (Additional file 6).

\section{Birthweight heaping and rounding}

Observer-assessed birthweight heaping was two-fold lower by digital $(15.7 \%)$ compared to analogue scales (36\%). Survey-report further increased heaping (digital $25.3 \%$, analogue 43.4\%). Register-record increased heaping by only $1.4 \%$ for digital scales and $1.1 \%$ for analogue (Table 4). Heaping indices were consistently lower for digital than analogue scales across all $500 \mathrm{~g}$ increments (Table 5), and higher during night than day shifts (Table 4). Re-allocation of $25 \%$ of $2500 \mathrm{~g}$ birthweights to the LBW category increased LBW prevalence by $2.0 \%$ for register-record and $2.5 \%$ for survey-report (Additional file 15). 
Table 1 Characteristics of babies and women observed in labour and delivery wards, EN-BIRTH study ( $n=23,471$ births)

\begin{tabular}{|c|c|c|c|c|c|c|}
\hline & Bangladest & & Nepal & Tanzania & & All sites \\
\hline & Azimpur & Kushtia & Pokhara & Temeke & Muhimbili & \\
\hline & $\begin{array}{l}\text { Tertiary } \\
\text { n (\%) }\end{array}$ & $\begin{array}{l}\text { District } \\
\text { n (\%) }\end{array}$ & $\begin{array}{l}\text { Regional } \\
\text { n (\%) }\end{array}$ & $\begin{array}{l}\text { Regional } \\
\text { n (\%) }\end{array}$ & $\begin{array}{l}\text { National } \\
\text { n (\%) }\end{array}$ & n (\%) \\
\hline Total Women & 2910 & 2412 & 7370 & 6748 & 3575 & 23,015 \\
\hline Women's Age & & & & & & \\
\hline$<18$ years & $25(0.9)$ & $3(0.1)$ & $311(4.2)$ & $26(0.4)$ & $8(0.2)$ & $373(1.6)$ \\
\hline 18-19years & $475(16.3)$ & $197(8.2)$ & $817(11.1)$ & $767(11.4)$ & $159(4.4)$ & $2415(10.5)$ \\
\hline 20-24 years & $1158(39.8)$ & 954 (39.6) & $3080(41.8)$ & $2314(34.3)$ & $722(20.2)$ & $8228(35.8)$ \\
\hline 25-29years & 867 (29.8) & $736(30.5)$ & $2114(28.7)$ & $1697(25.1)$ & $1134(31.7)$ & $6548(28.5)$ \\
\hline 30-34 years & $297(10.2)$ & $373(15.5)$ & $827(11.2)$ & $1146(17)$ & $924(25.8)$ & $3567(15.5)$ \\
\hline $35+$ years & $88(3)$ & $149(6.2)$ & $221(3)$ & $798(11.8)$ & $628(17.6)$ & $1884(8.2)$ \\
\hline Maternal education & & & & & & \\
\hline No Education & $39(1.3)$ & $77(3.2)$ & $268(3.6)$ & $202(3)$ & $66(1.8)$ & $652(2.8)$ \\
\hline Primary incomplete & $111(3.8)$ & $127(5.3)$ & $252(3.4)$ & $81(1.2)$ & $45(1.3)$ & $616(2.7)$ \\
\hline Primary complete & $339(11.6)$ & $347(14.4)$ & $302(4.1)$ & $31(0.5)$ & $5(0.1)$ & $1024(4.4)$ \\
\hline Secondary incomplete & 985 (33.8) & 954 (39.6) & $1637(22.2)$ & $4053(60.1)$ & $1299(36.3)$ & $8928(38.8)$ \\
\hline Secondary complete or higher & $1273(43.7)$ & $870(36.1)$ & $4509(61.2)$ & $2346(34.8)$ & $2146(60)$ & $11,144(48.4)$ \\
\hline Missing & $163(5.6)$ & $37(1.5)$ & $402(5.5)$ & $35(0.5)$ & $14(0.4)$ & $651(2.8)$ \\
\hline Parity & & & & & & \\
\hline Nullipara & $1350(46.4)$ & $1038(43)$ & $4402(59.7)$ & $2917(43.2)$ & $1363(38.1)$ & $11,070(48.1)$ \\
\hline Multipara & $56(1.9)$ & $5(0.2)$ & $6(0.1)$ & $13(0.2)$ & $3(0.1)$ & $83(0.4)$ \\
\hline Missing & $1504(51.7)$ & $1369(56.8)$ & $2961(40.2)$ & $3816(56.6)$ & $2207(61.8)$ & $11,857(51.5)$ \\
\hline Total Baby & 2936 & 2459 & 7442 & 6869 & 3765 & 23,471 \\
\hline Live Birth & $2895(99.5)$ & $2302(96.6)$ & $7171(98.1)$ & $6606(97.3)$ & $3490(94.5)$ & $22,464(97.3)$ \\
\hline Baby's condition at L\&D discharge & & & & & & \\
\hline Alive & $2895(99.5)$ & $2302(96.6)$ & $7171(98.1)$ & $6606(97.3)$ & $3490(94.5)$ & $22,464(97.3)$ \\
\hline Stillbirth & $11(0.3)$ & $74(3)$ & $126(1.7)$ & $153(2.2)$ & $186(3)$ & $550(2.2)$ \\
\hline Neonatal death & $1(0)$ & $6(0.3)$ & $4(0.1)$ & $28(0.4)$ & $19(0.5)$ & $58(0.3)$ \\
\hline Missing & $2(0.1)$ & $2(0.1)$ & $6(0.1)$ & $5(0.1)$ & $0(0)$ & $15(0.1)$ \\
\hline Baby number & & & & & & \\
\hline Single & $2864(98.3)$ & $2296(96.1)$ & $7185(98)$ & $6561(96.4)$ & $3336(90)$ & $22,242(96.1)$ \\
\hline Twin & $48(1.6)$ & $86(3.6)$ & $140(1.9)$ & $242(3.6)$ & $336(9.1)$ & $852(3.7)$ \\
\hline Triplets & $3(0.1)$ & $6(0.3)$ & $3(0)$ & $0(0)$ & $33(0.9)$ & $45(0.2)$ \\
\hline Mode of birth & & & & & & \\
\hline Normal vertex delivery & $784(26.7)$ & $1453(59.1)$ & $5889(79.1)$ & $6307(91.8)$ & $1616(42.9)$ & $16,049(68.4)$ \\
\hline Vaginal breech/Vacuum/ Forceps & $1(0)$ & $0(0)$ & $351(4.7)$ & $10(0.1)$ & $10(0.3)$ & $372(1.6)$ \\
\hline Caesarean section & $2142(73)$ & $996(40.5)$ & $1163(15.6)$ & $489(7.1)$ & $2105(55.9)$ & $6895(29.4)$ \\
\hline Missing & $9(0.3)$ & $10(0.4)$ & $39(0.5)$ & $63(0.9)$ & $34(0.9)$ & $155(0.7)$ \\
\hline Birthweight & & & & & & \\
\hline Extremely LBW < $1000 \mathrm{~g}$ & $1(0)$ & $7(0.3)$ & $27(0.4)$ & $13(0.2)$ & $44(1.2)$ & $92(0.4)$ \\
\hline Very LBW 1000-1499g & $1(0)$ & $27(1.2)$ & $38(0.5)$ & $22(0.3)$ & $159(4.5)$ & $247(1.1)$ \\
\hline LBW $1500-2499 \mathrm{~g}$ & $351(12.2)$ & $437(19.1)$ & $830(11.4)$ & $466(7.1)$ & $794(22.2)$ & $2878(12.7)$ \\
\hline All LBW $<2500 \mathrm{~g}$ (sum of above) & $353(12.2)$ & $471(20.6)$ & $895(12.3)$ & $501(7.6)$ & $997(27.9)$ & $3217(14.2)$ \\
\hline Not LBW $\geq 2500 \mathrm{~g}$ & $2528(87.5)$ & $1804(78.9)$ & $6274(86.5)$ & $6051(91.7)$ & $2549(71.4)$ & $19,206(85)$ \\
\hline
\end{tabular}


Table 1 Characteristics of babies and women observed in labour and delivery wards, EN-BIRTH study ( $n=23,471$ births) (Continued)

\begin{tabular}{|c|c|c|c|c|c|c|}
\hline & Bangladesh & & Nepal & Tanzania & & All sites \\
\hline & Azimpur & Kushtia & Pokhara & Temeke & Muhimbili & \\
\hline & $\begin{array}{l}\text { Tertiary } \\
\text { n (\%) }\end{array}$ & $\begin{array}{l}\text { District } \\
\text { n (\%) }\end{array}$ & $\begin{array}{l}\text { Regional } \\
\text { n (\%) }\end{array}$ & $\begin{array}{l}\text { Regional } \\
\text { n (\%) }\end{array}$ & $\begin{array}{l}\text { National } \\
\text { n (\%) }\end{array}$ & n (\%) \\
\hline Missing & $7(0.2)$ & $11(0.5)$ & $83(1.1)$ & $46(0.7)$ & $24(0.7)$ & $171(0.8)$ \\
\hline Sex & & & & & & \\
\hline Male & $1465(50.4)$ & $1220(51.3)$ & 3903 (53.6) & 3481 (51.5) & $1833(50.2)$ & $11,902(51.8$ \\
\hline Female & 1441 (49.6) & $1154(48.5)$ & $3369(46.2)$ & $3265(48.3)$ & 1813 (49.6) & $11,042(48.1)$ \\
\hline Ambiguous & $1(0)$ & $4(0.2)$ & $13(0.2)$ & $7(0.1)$ & $6(0.2)$ & $31(0.1)$ \\
\hline
\end{tabular}

\section{Objective 3: Barriers and enablers to routine recording}

All study hospital labour ward registers had a specific column to record birthweight, usually recorded in kilogrammes to 1 decimal place, despite the Bangladesh revised register column heading specifying the unit in grammes (Fig. 6).

IDIs were conducted with 40 nurse-midwives/doctors and 65 EN-BIRTH study data collectors and one FGD was conducted in each hospital $(n=5)$. Emerging themes functioning as both barriers or enablers in the five hospitals are shown in Fig. 7.

\section{Register design}

All respondents stated the labour ward register was adequately designed for birthweight measurement. Complexity of documentation systems was expressed by respondents as a barrier, since birthweight is also written in several other formal and informal documents. The order of birthweight documentation was first into the register in Bangladesh, while in Nepal and Tanzania birthweights were recorded in one to three other documents before the register (Additional file 16). a
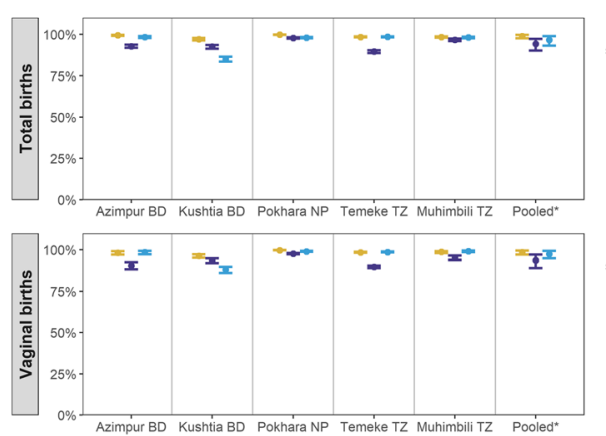

source $\rightarrow$ Observer-assessed - Survey-reported - Register-recorded

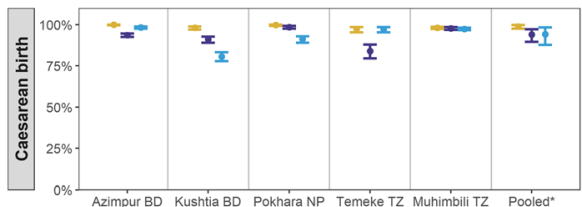
Observer-assessed
$\rightarrow-n=6733$ - Survey-reported - Register-recorded
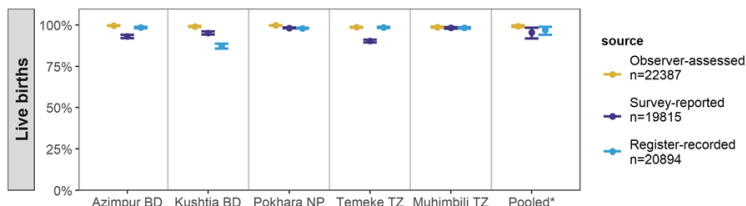

- Survey-reported

- Register-recorded
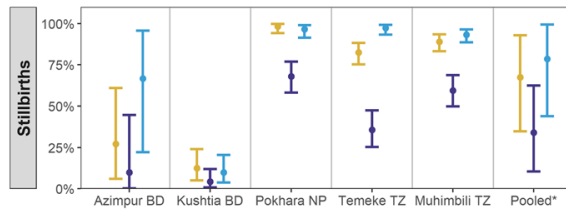

source

Source
Observer-assessed
$n=493$

$\rightarrow$ Survey-reported

n 375
- Register-recorded
$n=507$ b
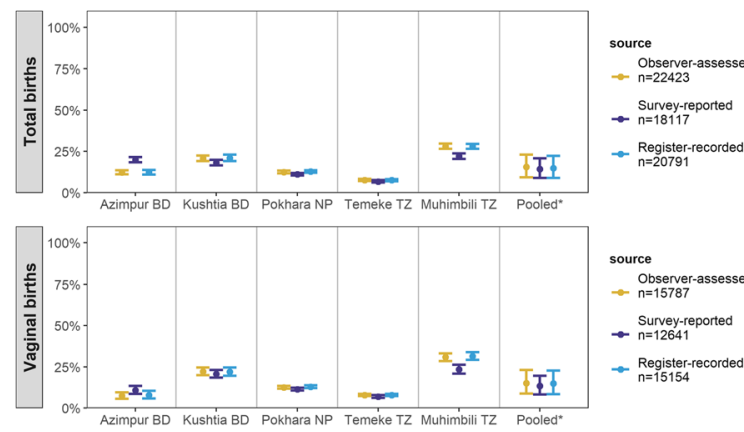

surce Observer-assessed
$n=15787$ - Survey-reported - Register-recorded

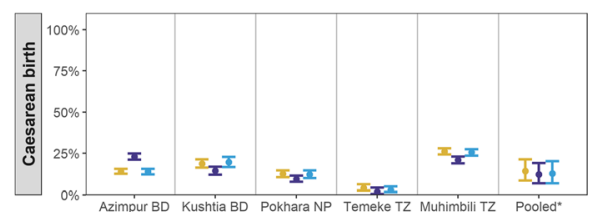
Observer-assessed
$n=6630$ - Survey-reported - Register-recorded

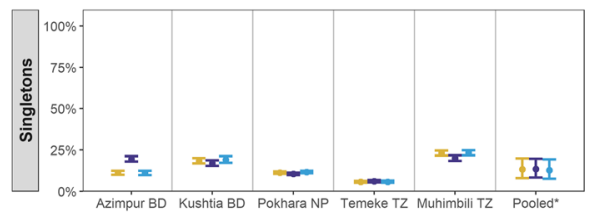
Observer-assessed Survey-report - Register-recorded

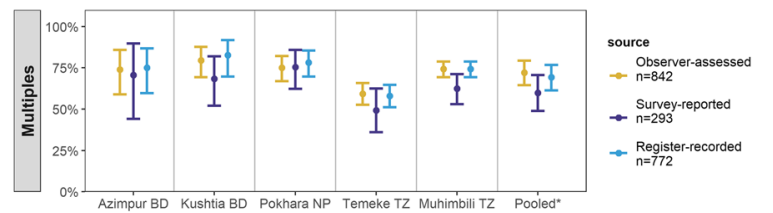

Fig. 3 a Coverage rates for babies weighed at birth and $\mathbf{b}$ prevalence of low birthweight newborns measured by observation, exit-survey and register, EN-BIRTH study. *Random effects. $\mathbf{a} n=22,880$ births, $\mathbf{b} n=22,423$ births. BD Bangladesh, NP Nepal, TZ Tanzania 
Table 2 Individual-level validation in surveys and registers for weighing coverage, EN-BIRTH study ( $n=23,471$ births)

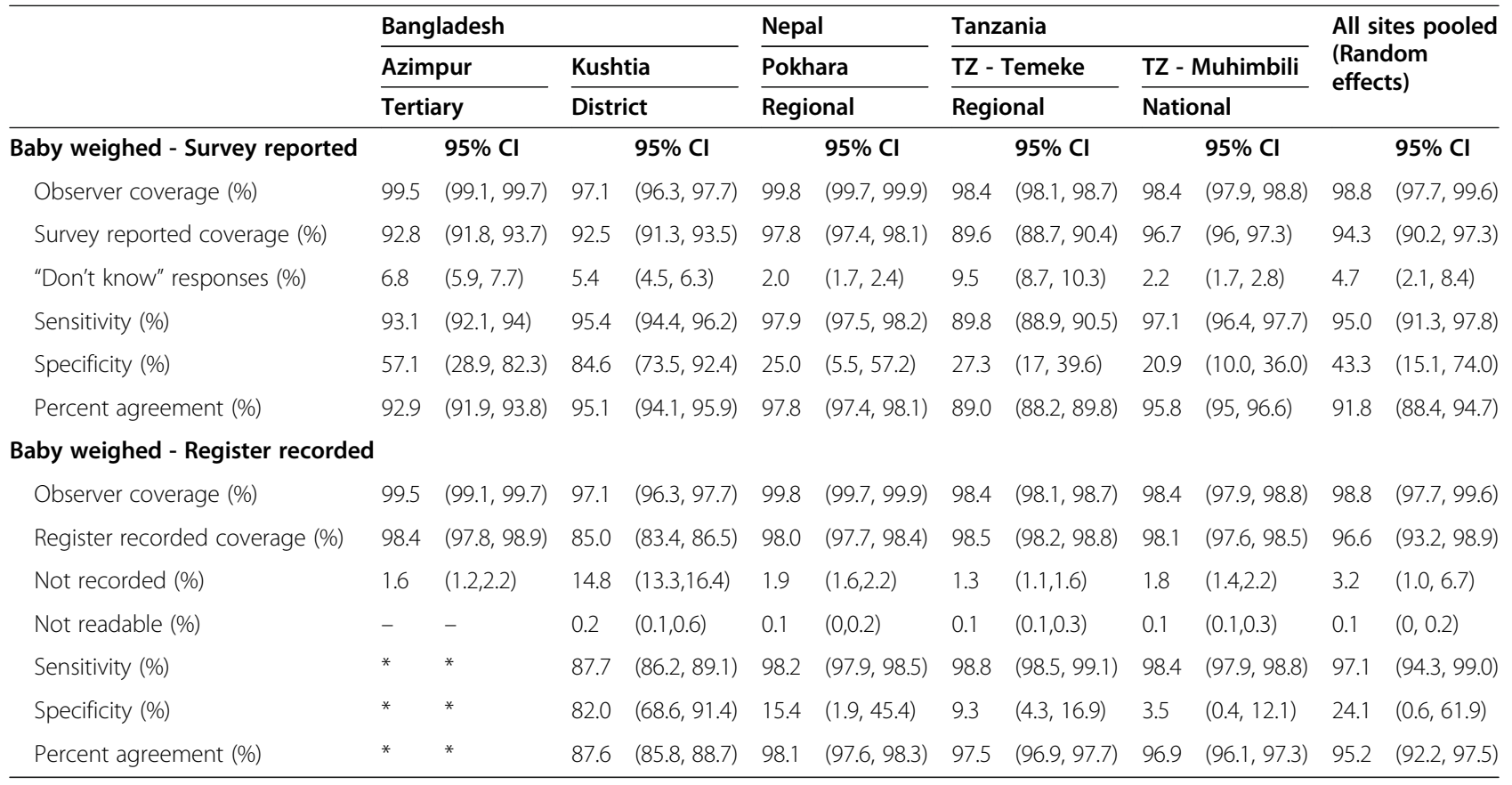

*Validity statistics suppressed where $<10$ count in either column of two-by-two table

- No observations

Percent agreement was calculated as the sum of true positives and true negatives divided by the total number of newborns: (TP + TN)/n. For survey-reported weighing coverage, we combined "don't know" with "no" answers. Survey validity results with "don't know" responses excluded are presented in Additional file 12. Two-way tables are presented in Additional file 19

\section{Register filling}

All respondents stated recording birthweight in labour ward registers is standard practice. Birthweight is usually written down by the same nurse-midwife who weighed the newborn, but only after providing all other care around the time of birth for mother and baby. Estimated time from weighing the newborn to birthweight register documentation averaged 4-31 min, up to a maximum of 1-3 h (Additional file 17). Shortage of time was a frequently measured barrier to high quality register documentation. EN-BIRTH data collectors described seeing that when busy, health workers may record the birthweight on a separate piece of paper, or ask the mother or another colleague to remember the weight, and transfer this weight later into formal documents. The baby may be weighed again if later no one can recall the birthweight.

The enabler of additional actors only available during the day shift was mentioned.

"Most of the time documentation was done appropriately because there were students who could offer assistance during the day. But it was very difficult during night shift because the midwife should do everything by herself like getting the birthweight, resuscitation ... when it comes to recording she will find that she has forgotten most of the information." -Health worker, Muhimbili TZ

EN-BIRTH study clinical observers commented on the barrier that health workers did not trust the precision of the weighing scales and sometimes used their personal judgement and rounded birthweights:

"If [the analogue scale] shows 4 kilo 300 grammes, they assume it [is] 4 kilo, 500 grammes."

-Data collector, Azimpur BD

\section{Register use}

Health workers acknowledged the importance of birthweight data and described its use for clinical care only:

"Information recording is critical and exact [numbers] should be recorded ... we take special care on managing babies with low birthweight, high birthweight ... [which] can require paediatrics consultation."

-Health worker, Pokhara NP

No respondent mentioned birthweight data for use higher up the health system. A barrier to use was expressed in the low level of trust in the birthweight data quality: 
Table 3 Individual-level validation in surveys and registers for LBW prevalence, EN-BIRTH study (23,471 births)

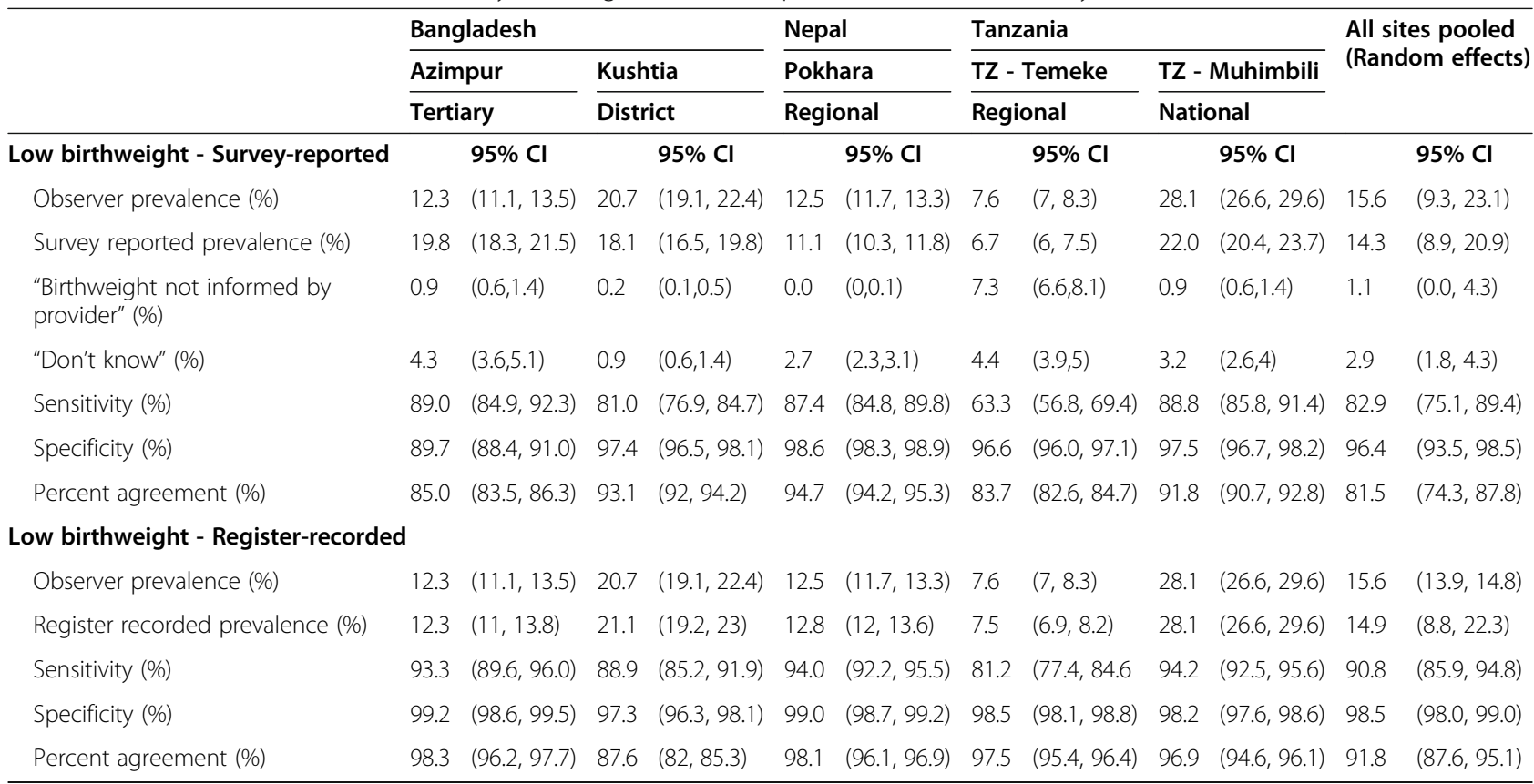

Don't know \% = proportion of women who answered "Don't Know" when asked the weight of their child

"Some nurses do not record the details after they have helped a mother to deliver ... if [documents are] not fully filled so people start to estimate, so this leads to non - accurate data about the weight of a child ... we sometimes fill not actual data."

-Health worker, Temeke TZ

\section{Discussion}

Birthweight measurement in our five CEmONC study hospitals was almost universal and routine facility registers measured coverage of weighing at birth and LBW classification more accurately than exit interview surveys. These findings align with our qualitative study in one EN-BIRTH hospital, Temeke TZ, which reported birthweight is highly valued by both health workers and mothers [25].

Routine registers' high completeness and accuracy for birthweight across all five hospitals was especially notable. Importantly, we found register records for LBW babies had both high sensitivity and specificity $>90 \%$, which was even higher than a study from Nigeria that reported sensitivity $62 \%$ and specificity $85 \%$ [20]. Birthweight coverage for babies of any birthweight (LBW and not LBW) similarly had high overall sensitivity of $97.1 \%$; however, specificity was very low (4-15\%) in three hospitals. We postulate this might be due to the baby being weighed and register documented

\begin{tabular}{|c|c|c|c|c|c|c|c|}
\hline & \multirow[b]{3}{*}{ Prevalence } & \multicolumn{2}{|c|}{ Bangladesh } & \multirow{3}{*}{$\begin{array}{l}\text { Nepal } \\
\text { Pokhara } \\
\text { Regional }\end{array}$} & \multicolumn{2}{|c|}{ Tanzania } & \multirow{3}{*}{ All sites pooled (Random effects) } \\
\hline & & Azimpur & Kushtia & & Temeke & Muhimbili & \\
\hline & & Tertiary & District & & Regional & National & \\
\hline \multirow{2}{*}{ Ratio: Survey: Observed } & Low birthweight & 1.62 & 0.87 & 0.89 & 0.88 & 0.78 & 0.97 \\
\hline & Normal birthweight & 0.91 & 1.03 & 1.02 & 1.01 & 1.08 & 1.01 \\
\hline \multirow{2}{*}{ Ratio: Register: Observed } & Low birthweight & 1.01 & 1.02 & 1.03 & 0.99 & 1 & 1.01 \\
\hline & Normal birthweight & 1 & 1 & 1 & 1 & 1 & 1 \\
\hline
\end{tabular}

\begin{tabular}{|llll}
\hline$<0.80$ & OR & $>1.20$ & Poor \\
\hline 0.80 to 0.84 & OR & 1.16 to 1.20 & Moderate \\
\hline 0.85 to 0.89 & OR & 1.11 to 1.15 & Good \\
\hline 0.90 to 0.94 & OR & 1.06 to 1.10 & Very Good \\
\hline 0.95 to 0.99 & OR & 1.00 to 1.05 & Excellent \\
\hline
\end{tabular}

Fig. 4 Validity ratios for survey-reported and register-recorded low/normal birthweight prevalence compared to observation, EN-BIRTH study. Heat-mapped using WHO's Data Quality Review (DQR) 5\%, 10\%, 15\% and 20\% cutoffs [30] 

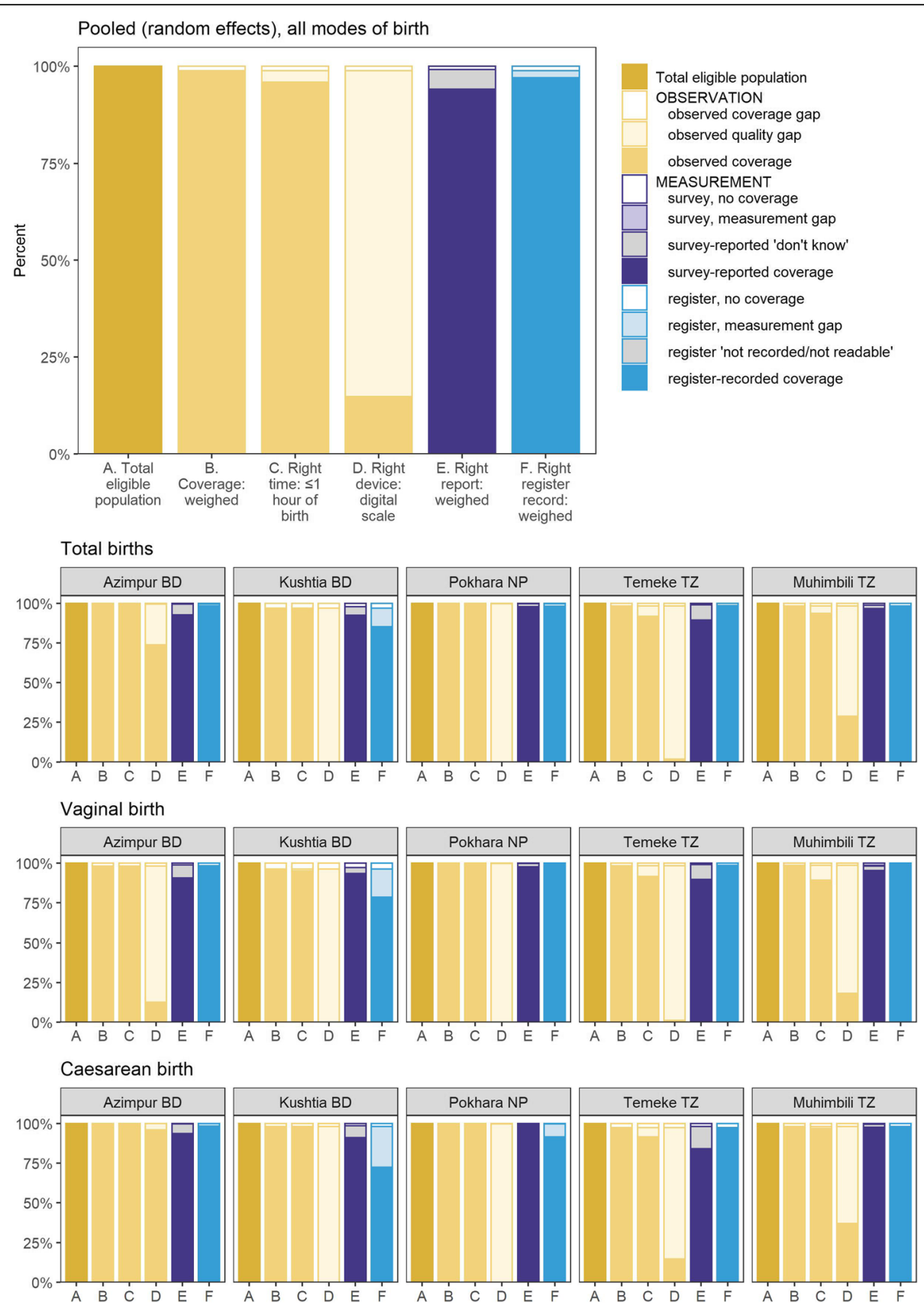

Fig. 5 Gap analysis for coverage and quality of weighing practice at birth, EN-BIRTH study $(n=23,471)$. Stratified by vaginal and caesarean births in EN-BIRTH study (observer assessed $n=23,471$, survey reported $n=20,349$, and register recorded $n=21,440$ ). BD Bangladesh, NP Nepal, TZ Tanzania

after observation had ceased (higher false positives). The exception was Kushtia BD's higher specificity of $82.0 \%$, which may relate to the lower register completeness overall (85.2\%) (higher true negatives). Register birthweight for LBW babies outperforming all birthweight babies may reflect the extra care given by health workers to the more vulnerable babies - for example, weighing more quickly after birth and thus being captured by the EN-BIRTH observers.
Survey-reported birthweight at the point of hospital discharge soon after birth was also accurate compared to observation. Our results align with a systematic review of 40 studies that showed high agreement between surveyrecalled and register-recorded birthweights as the standard [37]. For weighing coverage, survey-report compared to observation had high sensitivity but lower specificity. Similar to registers, this could be due to mothers' correct report of baby weighing after observation stopped. Survey- 


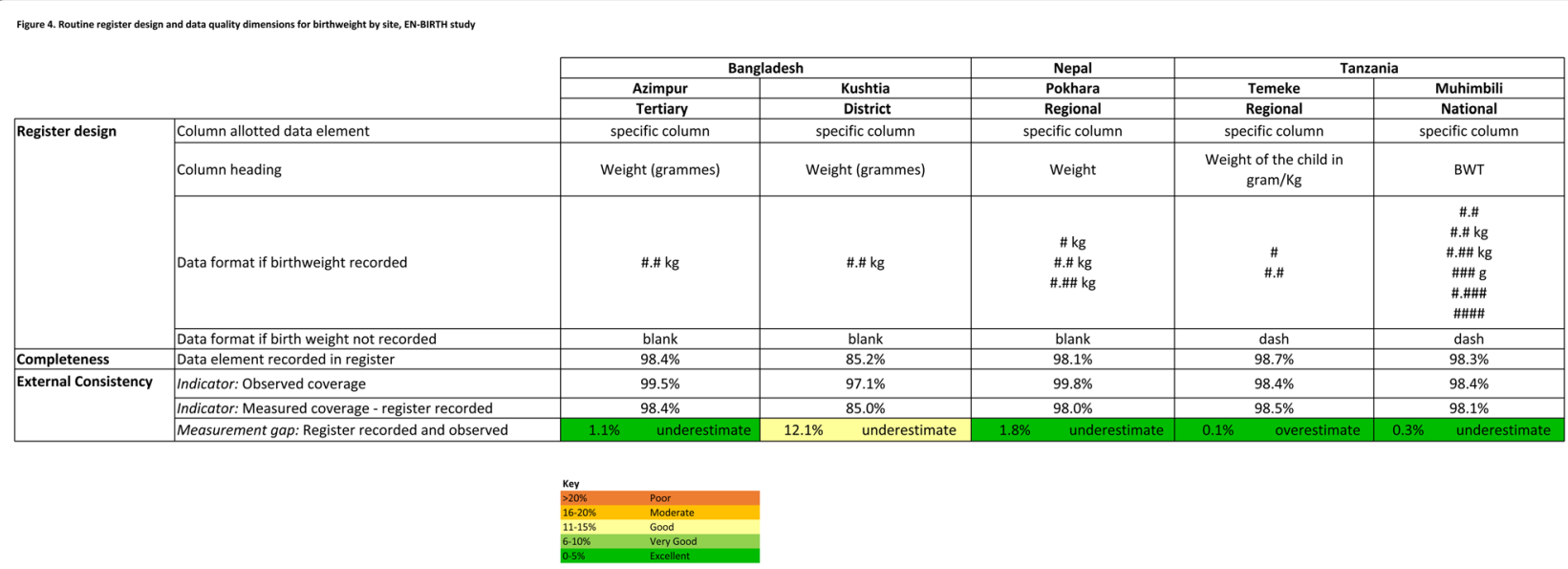

Fig. 6 Routine register design and data quality dimensions for birthweight by site, EN-BIRTH study. For basis of ranges, see WHO Data Quality Review [31]

report for LBW babies again outperformed their counterparts, likely for the same reasons of extra care given to LBW babies. This is in contrast to previous studies that revealed mixed but generally low accuracy for LBW prevalence, ranging from a sensitivity of $45 \%$ in a study conducted in Nepal to $71 \%$ in Kenya $[16,18,19,38]$. These validation studies evaluated survey report from soon after birth to household survey 22 months later.

Quality of birthweight measurement was mixed. Whilst liveborn babies had timely birthweights, we found quality gaps for other dimensions, especially the widely recognized heaping on multiples of $500 \mathrm{~g}[5,29,34]$. The ENBIRTH study design permitted exploration of cumulative heaping at different measurement capture points: the birthweight observation, exit interview and register-record. We found heaping increased slightly between observation and register-record despite the reality that usually the same health worker weighs and documents. Notably, heaping doubled when the same data were captured from women's report at exit interview. Obtaining a precise birthweight for all babies is fundamental. For instance, a baby whose true birthweight of $2480 \mathrm{~g}$ if rounded to $2500 \mathrm{~g}$ would not be correctly identified as LBW and fail to receive appropriate care. The same logic applies to identifying newborns weighing $2000 \mathrm{~g}$ or less, for whom kangaroo mother care is recommended.

The stillbirth birthweight gap was a striking finding in all hospitals except Pokhara NP. If gestational age is uncertain, the definition of stillbirth uses birthweight, vital for the minimum dataset for perinatal death surveillance and response to reduce preventable death [39]. As such, we suggest tracking coverage of stillbirth birthweight has potential as an indicator of respectful maternal and newborn care. More in-depth analyses regarding stillbirths in the EN-BIRTH study is reported separately [40].
Digital scale measurement gave lower heaping indices across all weights compared to analogue scales in our study. A 1980s Canadian study had postulated that digit bias was attributed to the use of analogue scales; however, a British study later found that significant rounding and truncation persisted even with digital scales $[41,42]$. Few published studies have explored the relationship between type of scale and LBW estimates. We found less heaping at $2500 \mathrm{~g}$ using digital scales, implying more babies would have been correctly classified as LBW. One previous study in India also found that the percentage of LBW babies identified by digital scales (29.5\%) was higher compared to analogue scales (23\%) [43].

In our study, two of five CEmONC hospitals were not, or rarely using, digital scales despite the relative low cost of these devices. This high usage of analogue scales remains a concern because heaping and rounding may be attributed to the instrument's imprecision and/or the health workers' subsequent lack of confidence in the measurement. Increasing the availability of digital scales at hospitals is important; however, some nurses stated their preference to use analogue scales because they were more familiar with these devices [44]. Thus, beyond providing digital scales, training and supportive supervision are required to improve quality of birthweight measurement. Our findings provide additional support to inform health system decisions to invest in digital scales for all facilities providing care at birth and improve accuracy of birthweight, especially LBW measurement.

High-quality care must be consistently provided during both day and night shifts. Our qualitative interview findings of lower availability of health workers under increased time pressure during night shifts lends explanation for poorer quality birthweight measurement 


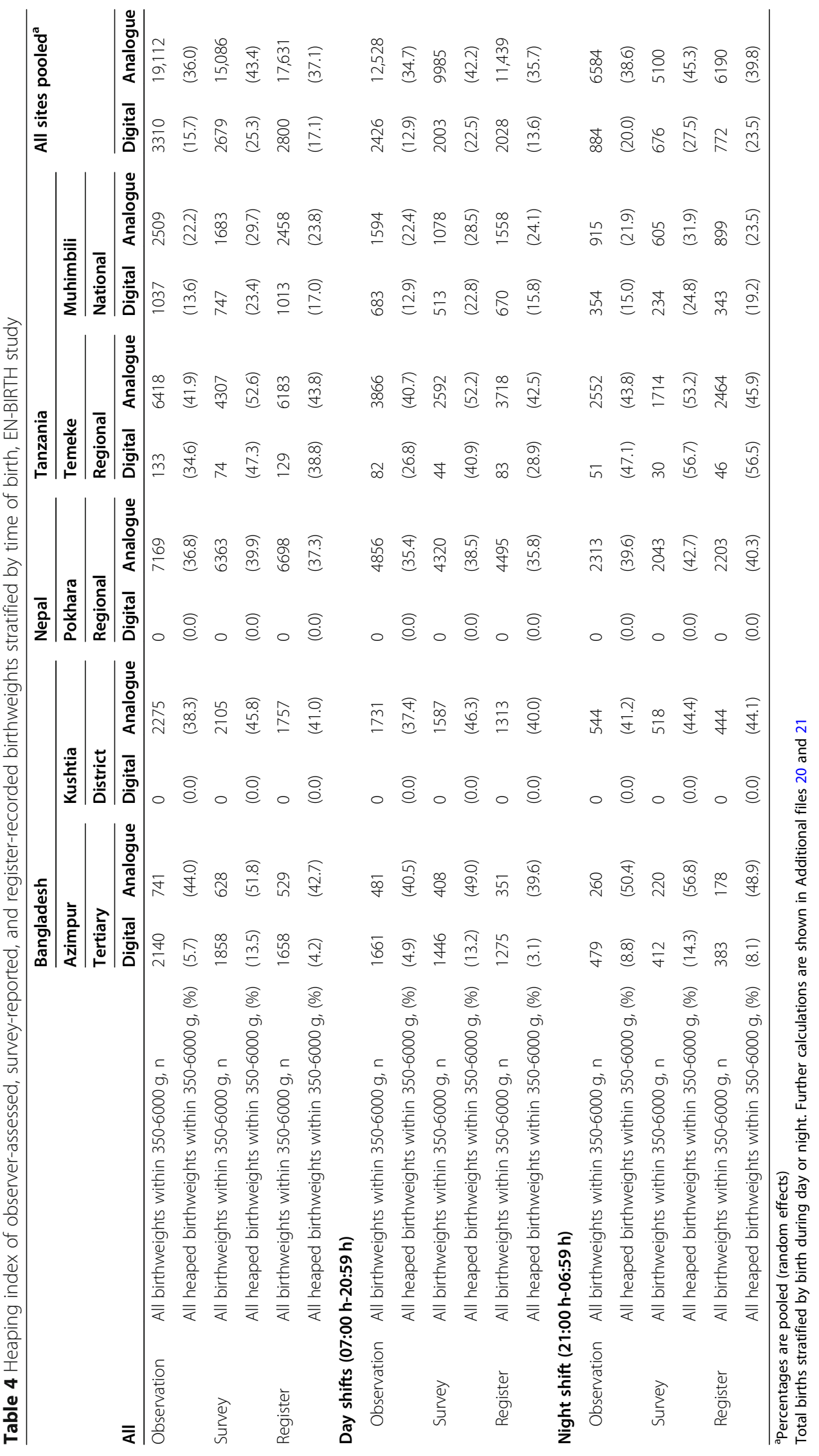




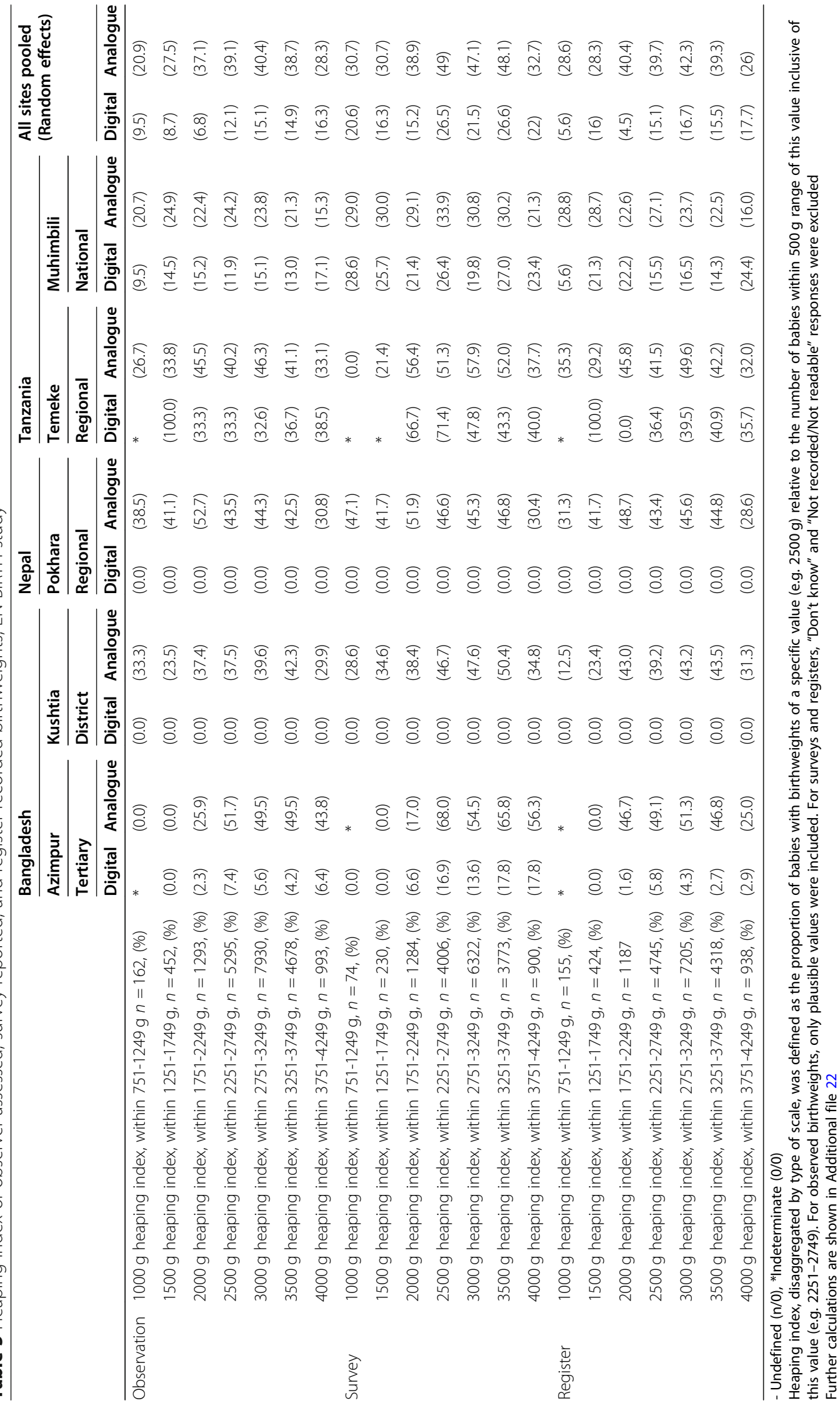




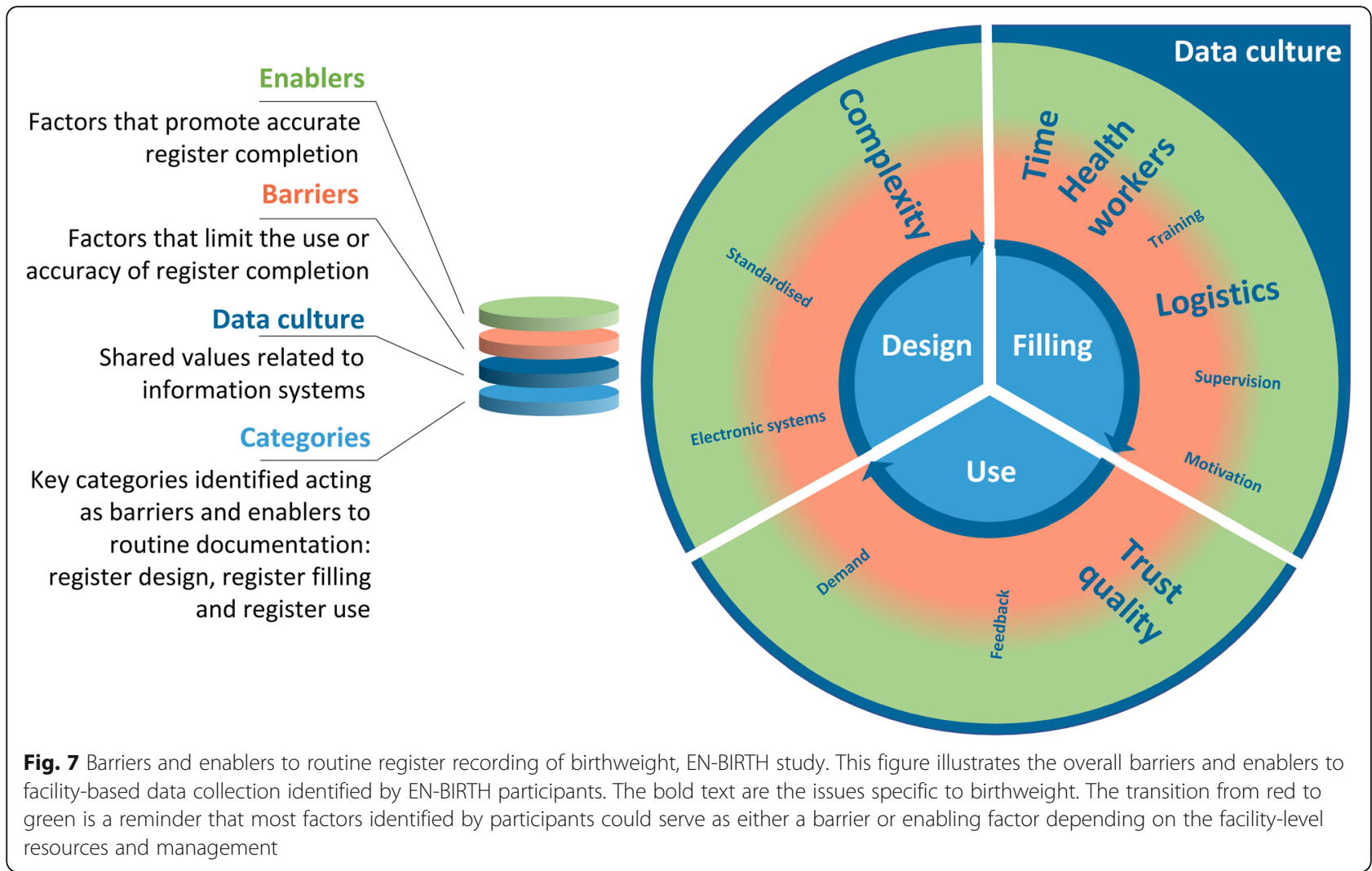

at night. We suggest that available hospital birthweight data, stratified by day/night time of birth, could be explored as a tracer indicator for measuring quality of care. Additionally, these data can be used to assess the needs for consistent staffing during all shifts, so midwives have sufficient support to complete care and documentation tasks in a timely manner.

We identified opportunities to improve quality of birthweight register data. In Bangladesh, although original and revised register designs both included birthweight, register-recorded completeness improved substantially after introduction of the revised register design. The improvement was seen in both hospitals in Bangladesh; however, it was lower in Kushtia BD, illustrating that design alone is not sufficient. In Azimpur BD, health workers continued to record birthweight in kilogrammes to one decimal place, despite the revised register instructions to measure in grammes. Logistical challenges of revised register stock-outs in Kushtia BD necessitated using original registers again during data collection. Improving feedback loops between health workers and those at other levels of the health system using facility birthweight data is critical. Feedback could increase understanding of how birthweight data are used, why accurate measurement is essential and how to address the opportunities to improve quality of birthweight measurement in LMIC settings.

\section{Strengths and limitations}

A major strength of this study was the multi-site, multi-country design using direct observation as gold standard to compare to register records and survey report. The large sample size of $>23,000$ facility births enabled diagnostic validation testing with stratification by normal and low birthweight and by mode of birth. Our observational gold standard was assessed by duplicate observation, and the effect of register recording completeness due to the presence of researchers was assessed by comparison with pre-study data extraction. Another strength is our inclusion of stillbirths, lending insight into an important public health issue, as often only live births are included when calculating birthweight indicators $[44,45]$. Although the changes in the Bangladesh registers midway were unexpected, this provided the opportunity to examine the results of a "natural experiment."

However, our study also had limitations. We did not observe whether scales were calibrated prior to birthweight, which could contribute to heaping. The clinical observers read the scale at the same time as the health worker and thus could have also contributed to the observed heaping. The data collection tablet app platform collected birthweight only in grammes, while health workers recorded in registers either kilogrammes or grammes. This may 
have introduced information bias, affecting birthweight in terms of accuracy and reliability and a missed opportunity to compare any effect of unit of measurement on birthweight data quality. For the purposes of calculating the heaping indices, we assumed that all the birthweights of interest were heaped despite a proportion of them being truly a multiple of $500 \mathrm{~g}$. We could not apply a correction for multiplicity.

Our findings of highly accurate register-recorded birthweights in CEmONC hospitals may not be generalizable to facilities at other levels of the health system. Moreover, our study intentionally focused on facility delivery; while the global facility delivery rate is $>80 \%$, in the EN-BIRTH study countries, it is only $37 \%$ in Bangladesh, 57\% in Nepal and 63\% in Tanzania [15, 46]. The validity of birthweight measurement in population-based studies has been addressed in a parallel study [47].

\section{Research gaps}

Globally, there remains a large gap between facility births and availability of birthweight data in routine systems in both south Asia (19.6\%) and sub-Saharan Africa (48.3\%) [48]. Further research regarding data flow and quality of aggregated facility birthweight data from facilities at all levels of the health system is critical.

Implementation research is also needed to explore how hospital birthweight data quality can be improved: using standardized weighing technique training to reduce heaping, utilizing calibrated digital scales and streamlining documentation. Even when stillbirths were weighed, women were not able to accurately report that weighing had happened. More research is required to better understand how information is provided to women following a stillbirth, and even if women are routinely allowed to see their stillborn baby. Since EN-BIRTH only assessed women's report at hospital exit, follow-up studies are needed to determine if exit surveyreported accuracy decays over time, considering household surveys are usually every $2-5$ years. Studies could be conducted to explore if household survey estimates of LBW are improved if birthweight is recorded on health cards given to parents, which they can show at the time of the survey [49].

\section{Conclusions}

We found high individual-level validity for coverage of weighing at birth and LBW classification in both registers and surveys, with the former outperforming the latter. Our results provide evidence supporting the use of both these data sources to increase the availability of birthweight data in LMICs. Surveys will remain an important data source especially in the most vulnerable populations, where deliveries mostly occur at home. Given the increase in facility births worldwide, birthweight data recorded in registers and incorporated into routine administrative systems can provide essential information for programs and policies. Currently, registers are an underused source of information. However, registers could offer a cost-efficient way to generate more frequent coverage measurements compared to intermittent population-based surveys. Register data completeness are already high. Closing data quality gaps for birthweight heaping will require standardised processes and ensuring facilities have sufficient staffing to carry out care and documentation in a timely manner. Only then will each and every newborn - even the smallest, sickest, and most marginalized - be counted and weighed, and countries have better data to track how many survive and thrive.

\section{Supplementary Information}

The online version contains supplementary material available at https://doi. org/10.1186/s12884-020-03355-3. Additional file 1. EN-BIRTH study sites - National mortality rates and
hospital context.

Additional file 2. EN-BIRTH study data collection dates by site and time elapsed between birth and exit survey.

Additional file 3. STROBE statement.

Additional file 4. EN-BIRTH data collection flow.

Additional file 5. EN-BIRTH implausible birthweights.

Additional file 6. Comparison of original vs. revised Bangladesh registers in EN-BIRTH.

Additional file 7. Inter-observer agreement (Kappa) for gold standard observational data, EN-BIRTH study.

Additional file 8. Labour ward register data extraction completeness comparison pre-study and during-study for EN-BIRTH.

Additional file 9. Weighing coverage and LBW prevalence, EN-BIRTH study (figure).

Additional file 10. Weighing coverage and LBW prevalence in EN-BIRTH study (table).

Additional file 11. Chi-squared test results comparing EN-BIRTH weighing coverage and LBW prevalence, disaggregated.

Additional file 12. EN-BIRTH study birthweight validation results.

Additional file 13. Bland-Altman plots comparing observed EN-BIRTH birthweights with survey-reported and register-recorded.

Additional file 14. Types of weighing scales used in EN-BIRTH study, Total denotes babies who were observed to be weighed.

Additional file 15. Adjusted LBW prevalence in exit surveys and routine registers, EN-BIRTH study.

Additional file 16. Interview results with data collectors and health workers on barriers and enablers checklist, EN-BIRTH study.

Additional file 17. EN-BIRTH interview results with data collectors and health workers on estimated time to complete documentation.

Additional file 18. Ethical approval of local institutional review boards, EN-BIRTH study. 
Additional file 19. Weighing and low birthweight indicators individuallevel validation showing two-way tables, EN-BIRTH study.

Additional file 20. EN-BIRTH birthweight heaping index and measurement ratios, day shift. Day shift $=07: 00-20: 59$.

Additional file 21. EN-BIRTH birthweight heaping index and measurement ratios, night shift. Night shift $=21: 00-06: 59$.

Additional file 22. EN-BIRTH birthweight heaping index.

\section{Abbreviations}

BD: Bangladesh; CEmONC: Comprehensive emergency obstetric and newborn care; CIFF: Children's Investment Fund Foundation; DHS: The Demographic and Health Surveys Program; EN-BIRTH: Every Newborn-Birth Indicators Research Tracking in Hospitals study; FGD: Focus Group Discussions; g: Grammes; HMIS: Health Management Information Systems; icddr,b: International Centre for Diarrheal Disease Research, Bangladesh; IHI: Ifakara Health Institute, Tanzania; LBW: Low Birthweight; LMIC: LowMiddle Income Country/countries; LSHTM: London School of Hygiene \& Tropical Medicine; MARCH Centre: Maternal, Adolescent, Reproductive \& Child Health Centre, LSHTM; MCHTI: Maternal and Child Health Training Institute, Azimpur, Bangladesh; MUHAS: Muhimbili University of Health and Allied Sciences, Tanzania; MICS: Multiple Indicator Cluster Survey; NMR: Neonatal Mortality Rate; NP: Nepal; PRISM: Performance of Routine Information System Management; SDG: Sustainable Development Goal; TZ: Tanzania; UNICEF: United Nations Children's Fund; WHO: World Health Organization

\section{Acknowledgements}

Firstly, and most importantly, we thank the women, their families, the health workers and data collectors. We credit the inspiration of the late Godfrey Mbaruku. We thank Claudia DaSilva, Veronica Ulaya, Mohammad Raisul Islam, Sudip Karki and Rabina Sarki for their administrative support and Sabrina Jabeen, Goutom Banik, Md. Shahidul Alam, Tamatun Islam Tanha and Md. Mohsiur Rahman for support during data collectors training. We acknowledge the following groups for their guidance and support: National Advisory Groups

Bangladesh: Mohammod Shahidullah, Khaleda Islam, Md Jahurul Islam. Nepal: Naresh P KC, Parashu Ram Shrestha.

Tanzania: Muhammad Bakari Kambi, Georgina Msemo, Asia Hussein, Talhiya Yahya, Claud Kumalija, Eliudi Eliakimu, Mary Azayo, Mary Drake, Honest Kimaro.

EN-BIRTH validation collaborative group:

Bangladesh: Md. Ayub Ali, Bilkish Biswas, Rajib Haider, Md. Abu Hasanuzzaman, Md. Amir Hossain, Ishrat Jahan, Rowshan Hosne Jahan, Jasmin Khan, M A Mannan, Tapas Mazumder, Md. Hafizur Rahman, Md. Ziaul Haque Shaikh, Aysha Siddika, Taslima Akter Sumi, Md. Taqbir Us Samad Talha. Tanzania: Evelyne Assenga, Claudia Hanson, Edward Kija, Rodrick Kisenge Karim Manji, Fatuma Manzi, Namala Mkopi, Mwifadhi Mrisho, Andrea Pembe. Nepal: Jagat Jeevan Ghimire, Rejina Gurung, Elisha Joshi, Avinash K Sunny, Naresh P. KC, Nisha Rana, Shree Krishna Shrestha, Dela Singh, Parashu Ram Shrestha, Nishant Thakur.

LSHTM: Hannah Blencowe, Sarah G Moxon.

EN-BIRTH Expert Advisory Group: Agbessi Amouzou, Tariq Azim, Debra Jackson, Theopista John Kabuteni, Matthews Mathai, Jean-Pierre Monet, Allisyn C Moran, Pavani K Ram, Barbara Rawlins, Jennifer Requejo, Johan Ivar Sæbø, Florina Serbanescu, Lara Vaz.

We are also very grateful to fellow researchers who peer-reviewed this paper.

\section{About this supplement}

This article has been published as part of BMC Pregnancy and Childbirth Volume 21 Supplement 1, 2021: Every Newborn BIRTH multi-country valid ation study: informing measurement of coverage and quality of maternal and newborn care. The full contents of the supplement are available online at https://bmcpregnancychildbirth.biomedcentral.com/articles/supplements/ volume-21-supplement-1.

\section{Authors' contributions}

The EN-BIRTH study was conceived by JEL, who acquired the funding and led the overall design with support from HR. Each of the three country research teams input to design of data collection tools and review processes, data collection and quality management with technical coordination from $\mathrm{HR}$, GRGL, and DB. The iccdr,b team (notably AER, TT, TH, QSR, SA and SBZ) led the development of the software application, data dashboards and database development with VG and the LSHTM team. IHI (notably DS) coordinated work on barriers and enablers for data collection and use, working closely with LTD. QSR was the main lead for data management working closely with OB, KS and LTD. For this paper, SK and LTD led the analyses and first draft of manuscript working closely with KP, PM, HB, and JEL. All authors (SK, LTD, SBZ, KP, NS, AKS, DS, QSR, AKC, HR, SEA, PM, MEG, HB, JEL) revised the manuscript and gave final approval of the version to be published and agree to be accountable for the work. The EN-BIRTH study group authors made contributions to the conception, design, data collection or analysis or interpretation of data. This paper is published with permission from the Directors of Ifakara Health Institute, Muhimbili University of Health and Allied Sciences, icddr,b and Golden Community. The authors' views are their own, and not necessarily from any of the institutions they represent. EN-BIRTH Study Group: Bangladesh: Qazi Sadeq-ur Rahman, Ahmed Ehsanur Rahman, Tazeen Tahsina, Sojib Bin Zaman, Shafiqul Ameen, Tanvir Hossain, Abu Bakkar Siddique, Aniqa Tasnim Hossain, Tapas Mazumder, Jasmin Khan, Taqbir Us Samad Talha, Rajib Haider, Md. Hafizur Rahman, Anisuddin Ahmed, Shams El Arifeen. Nepal: Omkar Basnet, Avinash K Sunny, Nishant Thakur, Rejina Gurung, Anjani Kumar Jha, Bijay Jha, Ram Chandra Bastola, Rajendra Paudel, Asmita Paudel, Ashish KC. Tanzania: Nahya Salim, Donat Shamba, Josephine Shabani, Kizito Shirima, Menna Narcis Tarimo, Godfrey Mbaruku (deceased), Honorati Masanja. LSHTM: Louise T Day, Harriet Ruysen, Kimberly Peven, Vladimir Sergeevich Gordeev, Georgia R Gore-Langton, Dorothy Boggs, Stefanie Kong, Angela Baschieri, Simon Cousens, Joy E Lawn.

\section{Funding}

The Children's Investment Fund Foundation (CIFF) are the main funder of the EN-BIRTH Study and funding is administered via The London School of Hygiene \& Tropical Medicine. The Swedish Research Council specifically funded the Nepal site through Lifeline Nepal and Golden Community. We acknowledge the core funders for all the partner institutions. Publication of this manuscript has been funded by CIFF. CIFF attended the study design workshop but had no role in data collection, analysis, data interpretation, report writing or decision to submit for publication. The corresponding author had full access to study data and final responsibility for publication submission decision.

\section{Availability of data and materials}

The datasets generated during and/or analysed during the current study are available on LSHTM Data Compass repository, https://datacompass.lshtm.ac. uk/955/

\section{Ethics approval and consent to participate}

This study was granted ethical approval by institutional review boards in all operating counties in addition to the London School of Hygiene \& Tropical Medicine (Additional file 18).

Voluntary informed written consent was obtained from all observed participants, their families for newborns, and respondents for the qualitative interviews. Participants were assured of anonymity and confidentiality. All women were provided with a description of the study procedures in their preferred language at admission, and offered the right to refuse, or withdraw consent at any time during the study. Facility staff were identified before data collection began and no health worker refused to be observed whilst providing care.

EN-BIRTH is study number 4833, registered at https://www.researchregistry.com.

\section{Consent for publication}

Not applicable.

\section{Competing interests}

The authors declare that they have no competing interests.

\section{Author details}

${ }^{1}$ Centre for Maternal, Adolescent, Reproductive \& Child Health (MARCH), London School of Hygiene \& Tropical Medicine (LSHTM), London, UK. ${ }^{2}$ Maternal and Child Health Division, International Centre for Diarrhoeal Disease Research, Bangladesh (icddr,b), Dhaka, Bangladesh. ${ }^{3}$ Florence Nightingale Faculty of Nursing, Midwifery \& Palliative Care, King's College 
London, London, UK. ${ }^{4}$ Department of Paediatrics and Child Health, Muhimbili University of Health and Allied Sciences (MUHAS), Dar Es Salaam, Tanzania. ${ }^{5}$ Department of Health Systems, Impact Evaluation and Policy, Ifakara Health Institute (IHI), Dar es Salaam, Tanzania. ${ }^{6}$ Golden Community, Lalitpur, Nepal. ${ }^{7}$ Department of Women's and Children's Health, Uppsala University, Uppsala, Sweden. ${ }^{8}$ Department of Infectious Disease Epidemiology, Faculty of Epidemiology and Public Health, London School of Hygiene and Tropical Medicine, London, UK.

\section{Published: 26 March 2021}

\section{References}

1. World Health Organization: Reproductive Health Indicators: Guidelines for Their Generation, Interpretation, and Analysis for Global Monitoring. https:// www.who.int/reproductivehealth/publications/monitoring/924156315x/en/. Accessed 14 Aug 2020.

2. World Health Organization: Global Targets 2025. https://www.who.int/ nutrition/global-target-2025/en/]. Accessed 9 Dec 2019.

3. UNICEF, WHO: UNICEF-WHO low birthweight estimates: levels and trends 2000-2015. https://www.unicef.org/reports/UNICEF-WHO-low-birthweightestimates-2019/. Accessed 14 Aug 2020

4. World Health Organization: Survive and Thrive: Transforming Care for Every Small and Sick Newborn. https://www.unicef.org/reports/transforming-carefor-every-small-and-sick-newborn-2020. Accessed 13 Aug 2020.

5. Blencowe H, Krasevec J, de Onis M, Black RE, An X, Stevens GA, Borghi E, Hayashi C, Estevez D, Cegolon L, et al. National, regional, and worldwide estimates of low birthweight in 2015, with trends from 2000: a systematic analysis. Lancet Glob Health. 2019;7(7):e849-60.

6. Gu H, Wang L, Liu L, Luo X, Wang J, Hou F, Nkomola PD, Li J, Liu G, Meng $\mathrm{H}$, et al. A gradient relationship between low birth weight and IQ: a metaanalysis. Sci Rep. 2017;7(1):18035

7. Christian P, Lee SE, Donahue Angel M, Adair LS, Arifeen SE, Ashorn P, Barros $\mathrm{FC}$, Fall $\mathrm{CH}$, Fawzi WW, Hao W, et al. Risk of childhood undernutrition related to small-for-gestational age and preterm birth in low- and middleincome countries. Int J Epidemiol. 2013;42(5):1340-55.

8. Risnes KR, Vatten LJ, Baker JL, Jameson K, Sovio U, Kajantie E, Osler M, Morley R, Jokela M, Painter RC, et al. Birthweight and mortality in adulthood: a systematic review and meta-analysis. Int J Epidemiol. 2011;40(3):647-61.

9. UN-IGME. A Neglected Tragedy - The global burden of stillbirths 2020 . https://www.unicef.org/media/84851/file/UN-IGME-the-global-burden-ofstillbirths-2020.pdf. Accessed 25 Oct 2020.

10. World Health Organization: Global Reference List of 100 Core Health Indicators (plus health-related SDGs). https://www.who.int/healthinfo/ indicators/2018/en/. Accessed 13 Aug 2020.

11. Blencowe H, Cousens S, Chou D, Oestergaard M, Say L, Moller A-B, Kinney M, Lawn J, Born Too Soon Preterm Birth Action G. Born too soon: the global epidemiology of 15 million preterm births. Reprod Health. 2013;10(Suppl 1):S2.

12. UNICEF, WHO: Every Newborn; An Action Plan to End Preventable Deaths. https://www.who.int/maternal_child_adolescent/newborns/every-newborn/ en/. Accessed 22 Dec 2018.

13. MEASURE Evaluation: Birthweight Specific Neonatal Mortality Rate (BWSNMR). https://www.measureevaluation.org/prh/rh_indicators/womenshealth/nb/birth-weight-specific-mortality-rate-bwsmr. Accessed 9 Dec 2019.

14. Lawn JE, Gravett MG, Nunes TM, Rubens CE, Stanton C, the GRG. Global report on preterm birth and stillbirth (1 of 7): definitions, description of the burden and opportunities to improve data. BMC Pregnancy Childbirth. 2010;10(1):S1.

15. UNICEF: The State of the World's Children 2019. Children, Food and Nutrition: Growing well in a changing world. https://www.unicef.org/sowc/. Accessed 13 Aug 2020

16. Blanc AK, Warren C, McCarthy KJ, Kimani J, Ndwiga C, RamaRao S. Assessing the validity of indicators of the quality of maternal and newborn health care in Kenya. J Glob Health. 2016;6(1):010405.

17. Blanc AK, Diaz C, McCarthy KJ, Berdichevsky K. Measuring progress in maternal and newborn health care in Mexico: validating indicators of health system contact and quality of care. BMC Pregnancy Childbirth. 2016;16(1):255.

18. McCarthy KJ, Blanc AK, Warren CE, Kimani J, Mdawida B, Ndwidga C. Can surveys of women accurately track indicators of maternal and newborn care? A validity and reliability study in Kenya. J Glob Health. 2016;6(2): 020502
19. Chang KT, Mullany LC, Khatry SK, Le-Clerq SC, Munos MK, Katz J. Validation of maternal reports for low birthweight and preterm birth indicators in rural Nepal. J Glob Health. 2018;8(1):2047-978.

20. Bhattacharya AA, Umar N, Audu A, Felix H, Allen E, Schellenberg JRM, Marchant T. Quality of routine facility data for monitoring priority maternal and newborn indicators in DHIS2: a case study from Gombe state, Nigeria. PLoS One. 2019;14(1):e0211265.

21. Moxon SG, Ruysen H, Kerber KJ, Amouzou A, Fournier S, Grove J, Moran AC, Vaz. $L M$, Blencowe H, Conroy N. Count every newborn; a measurement improvement roadmap for coverage data. BMC Pregnancy Childbirth. 2015;15(2):S8.

22. Jolivet RR, Moran AC, O'Connor M, Chou D, Bhardwaj N, Newby H, Requejo J, Schaaf M, Say L, Langer A. Ending preventable maternal mortality: phase II of a multi-step process to develop a monitoring framework, 2016-2030. BMC Pregnancy Childbirth. 2018;18(1):258.

23. Day LT, Ruysen H, Gordeev VS, Gore-Langton GR, Boggs D, Cousens S, Moxon SG, Blencowe H, Baschieri A, Rahman AE, et al. "Every NewbornBIRTH" protocol: observational study validating indicators for coverage and quality of maternal and newborn health care in Bangladesh, Nepal and Tanzania. J Glob Health. 2019;9(1):010902.

24. Day LT, Rahman QS, Rahman AE, Salim N, KC A, Ruysen H, Tahsina T, Masanja H, Basnet O, Gore-Langton GR, et al. Assessment of the validity of the measurement of newborn and maternal health-care coverage in hospitals (EN-BIRTH): an observational study. Lancet Glob Health. 2020. https://doi.org/10.1016/S2214-109X(20)30504-0.

25. Gladstone ME, Salim N, Ogillo K, Shamba D, Gore-Langton GR, Day LT, Blencowe H, Lawn JE. Birthweight measurement processes and perceived value: qualitative research in one EN-BIRTH study hospital in Tanzania. BMC Pregnancy Childbirth. 2021. https://doi.org/10.1186/s12884-020-03356-2.

26. Ruysen H, Rahman AE, Rahman QS, Zaman SB, Hossain T, Basnet O, Shirima K, Gordeev VS, Arifeen SE, Lawn JE. Electronic data collection for multicountry, hospital-based clinical observation of maternal and newborn care: experiences from the EN-BIRTH study. BMC Pregnancy Childbirth. 2021. https://doi.org/10.1186/s12884-020-03426-5.

27. StataCorp. Stata Statistical Software: Release 16. College Station: Stata Press; 2019.

28. R Core Team. R: A language and environment for statistical computing Vienna: R Foundation for Statistical Computing; 2013.

29. Day LT, Gore-Langton GR, Rahman AE, Basnet O, Shabani J, Tahsina T, Poudel A, Shirima K, Ameen S, Ashish KC, et al. Labour \& Delivery register data availability, quality, and utility: Every Newborn-Birth Indicators Research Tracking in Hospitals (EN-BIRTH) study baseline analysis in three countries. BMC Health Serv Res. 2020;20(1):737.

30. World Health Organization: Data quality review: a toolkit for facility data quality assessment. Module 2: Desk review of data quality. https://apps.who. int/iris/handle/10665/259225. Accessed 01 July 2019.

31. World Health Organization: Data quality review: a toolkit for facility data quality assessment. Module 2: Desk review of data quality. https://apps.who. int/iris/handle/10665/259225. Accessed 1 July 2019.

32. Munos MK, Blanc AK, Carter ED, Eisele TP, Gesuale S, Katz J, Marchant T, Stanton CK, Campbell H, Improving Coverage Measurement G. Validation studies for population-based intervention coverage indicators: design, analysis, and interpretation. J Glob Health. 2018;8(2):020804.

33. Bland JM, Altman DG. Measuring agreement in method comparison studies. Stat Methods Med Res. 1999;8(2):135-60.

34. Blanc AK, Wardlaw T. Monitoring low birth weight: an evaluation of international estimates and an updated estimation procedure. Bull World Health Organ. 2005;83(3):178-85.

35. Aqil A, Lippeveld T, Hozumi D. PRISM framework: a paradigm shift for designing, strengthening and evaluating routine health information systems. Health Policy Plan. 2009;24(3):217-28.

36. Shamba D, Day L, Zaman S, Khan J, Talha T, Rahman M, Kayastha A, Thakur $\mathrm{N}$, Tarimo M, Singh N. Barriers and enablers to routine register data collection for newborns and mothers: EN-BIRTH multi-country study. BMC Pregnancy Childbirth. 2021. https://doi.org/10.1186/s12884-020-03517-3.

37. Shenkin SD, Zhang MG, Der G, Mathur S, Mina TH, Reynolds RM. Validity of recalled $\mathrm{v}$. recorded birth weight: a systematic review and meta-analysis. J Dev Orig Health Dis. 2017;8(2):137-48.

38. Duffy S, Crangle M. Delivery room logbook - fact or fiction? Trop Dr. 2009; 39(3):145-9.

39. Blencowe $H$, Cousens $S$, Jassir FB, Say L, Chou D, Mathers C, Hogan D, Shiekh S, Qureshi ZU, You D, et al. National, regional, and worldwide 
estimates of stillbirth rates in 2015, with trends from 2000: a systematic analysis. Lancet Glob Health. 2016;4(2):e98-e108.

40. Peven K, Day LT, Ruysen H, Tahsina T, Ashish KC, Shabani J, Kong S, Ameen S, Basnet O, Haider R, et al. Stillbirths including intrapartum timing: ENBIRTH multi-country validation study. BMC Pregnancy Childbirth. 2021. https://doi.org/10.1186/s12884-020-03238-7.

41. Edouard L, Senthilselvan A. Observer error and birthweight: digit preference in recording. Public Health. 1997;111(2):77-9.

42. Emmerson AJ, Roberts SA. Rounding of birth weights in a neonatal intensive care unit over 20 years: an analysis of a large cohort study. BMJ Open. 2013:3(12):e003650.

43. Rekha C, Whelan RM, Reddy P, Reddy PS. Evaluation of adjustment methods used to determine prevalence of low birth-weight babies at a rural hospital in Andhra Pradesh, India. Indian J Public Health. 2013;57(3):177-80.

44. UNICEF: Low birthweight. https://data.unicef.org/topic/nutrition/lowbirthweight/. Accessed 20 Jan 2020.

45. Croft TN, Marshall AMJ, Allen CK, et al. Guide to DHS Statistics: DHS-7 (version 2). https://www.dhsprogram.com/pubs/pdf/DHSG1/Guide_to_DHS_ Statistics_DHS-7_v2.pdf. Accessed 20 Sept 2020.

46. World Health Organization: WHO GHO and Data Portal for Global Strategy. http://apps.who.int/gho/data/node.gswcah. Accessed 7 Jan 2020.

47. Biks GA, Blencowe H, Hardy VP, Misganaw B, Angaw DA, Wagnew A, Abebe SM, Guadu T, Martins J, Fisker AB, et al. Birthweight data completeness and quality in population-based surveys: EN-INDEPTH study. BMC Popul Health Metrics. 2020. https://doi.org/10.1186/s12963-020-00229-w.

48. Day LT, Blencowe H, Carvajal-Aguirre L, Chavula K, Guenther T, Gupta G Jackson D, Kinney M, Monet J-P, Moran A, et al. Survive and tehrive: transforming care for every small and sick newborn https://www.uniceforg/ reports/transforming-care-for-every-small-and-sick-newborn-2020. Accessed 13 Aug 2020.

49. UNICEF: Low birthweight. https://data.unicef.org/topic/nutrition/lowbirthweight/. Accessed 20 Jan 2020.

\section{Publisher's Note}

Springer Nature remains neutral with regard to jurisdictional claims in published maps and institutional affiliations.

Ready to submit your research? Choose BMC and benefit from:

- fast, convenient online submission

- thorough peer review by experienced researchers in your field

- rapid publication on acceptance

- support for research data, including large and complex data types

- gold Open Access which fosters wider collaboration and increased citations

- maximum visibility for your research: over $100 \mathrm{M}$ website views per year

At $\mathrm{BMC}$, research is always in progress.

Learn more biomedcentral.com/submissions 